A maior purpose of the Technical Information Center is to provide the broadest dissemination possible of information contained in DOE's Research and Development Reports to buisiness, industry, the academic community, and federal, state and local governments.

Although a small portion of this report is not reproducible, it is being made available to expedite the availability of information on the research discussed herein. 
TITLE MASS TRANSPURT' IN FROPAGATIN( PATTERNS IF C.ONVECTION

LA-UR- $-88-3680$

DE89 003476

AUTHOAIS

El Iuha Moses ind Victor Stelnberg

SUBMITtED to Physici D (Proceedings int the conterence on Advances in Fluld Turbulence, losi Alamos, New Mextco, May 16-20, 1988)

\section{DISX'I.AIMER}

This report was prepared as an uccuount of work spmons:-icd by an agency of the I Inited siates Ciswernment Neither the United Siates firwernment mor any agercy thereul, nul uny of their employeen. makex any warranty. enpress or unphod, or anumes uny legal liuhility or responaihility for the ncturacy, completenest, ur usefulness of any informalum. apouralus, product, or proxess diselined. or reprements that lix use woukl met infringe privateiy ownal rights Refer.

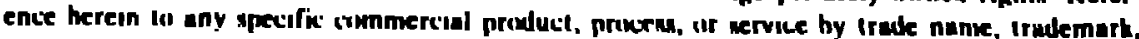

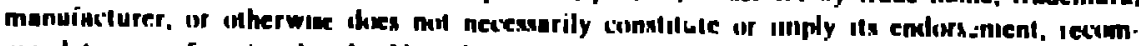

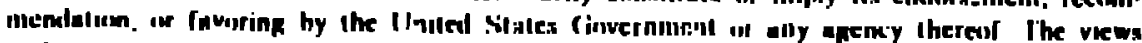

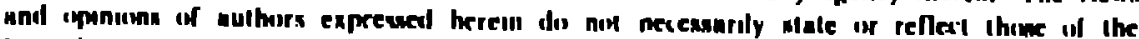
IIniterl Sintes fiewernnient or any apency thereorf
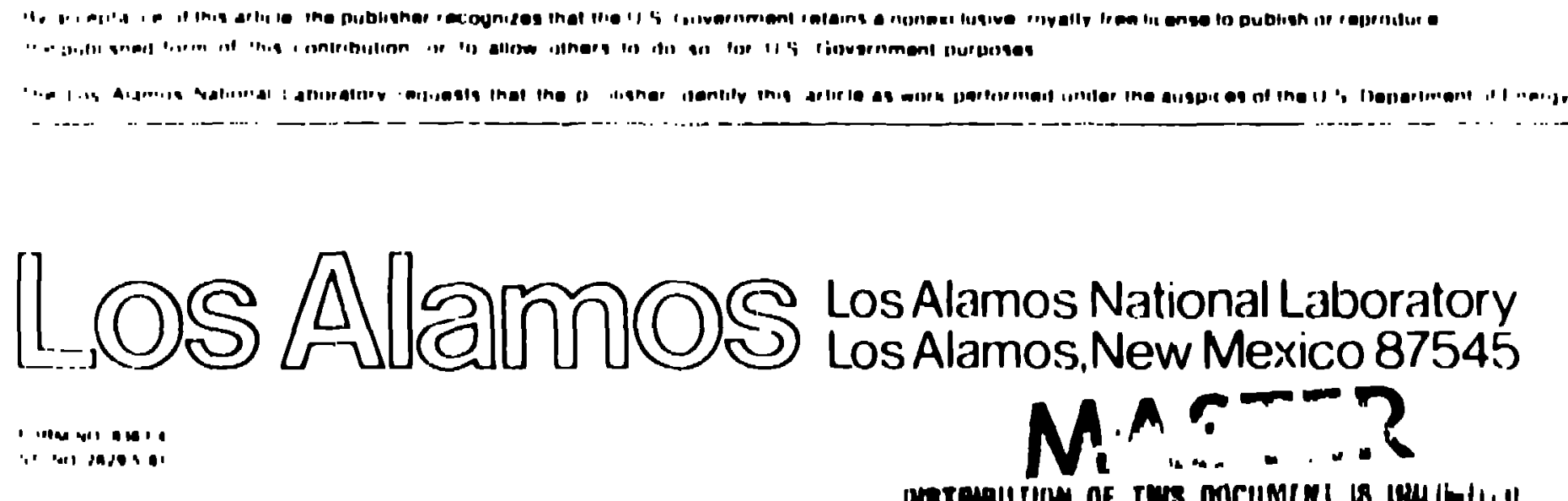


\title{
Mass 'Transport in Propagating Patterns of Convection
}

\author{
Elisha Moses ${ }^{(a)}$ and Yictor Steimberg ${ }^{(a)(b)}$ \\ (a) Department of Nuclear Physics \\ Weizmann Institute of Scicnce \\ Rehovot, 70100, Israel \\ (b) CNLS, Los Alamos National Laboratory \\ Unversity of California, \\ Los Alamos, N, 87545, U.S.A.
}

\section{Introduction}

Recent studies of propagating waves in an oscillntory convection of binnry mixtures $^{1-7}$ arise questions about transport properties of this flow. Opticnl visualizntion of a field of refraction index due to a shadowgraph technique given information on the temperature and concentration fields. However, experimental observation of rolls propagating along the cell as travelling wnves (TW) does not uecessnrily imply that mass is transferred hydrodynamically by the convertive motion along the coll. ()ne of the possibilities discusaed, e.g., is that TW observed is only n plinse propngation. The" traditional e.inmples of such situations come from the domnin of linenr, superpositionoriented physics. Acoustic waves transfer momentum and energy, but do not cnuse the mass to make excursions from their equilibrium point that are Inrger than the oscillntion amplitude. In the ease of nonlinenr physice we were nware that amnll amplitude surfare: whven cnure ouly small oscillntory motion round the equilibrium point, while larger mu plitudes can cause the mas to start moving in the direrlion of the 'I'W.

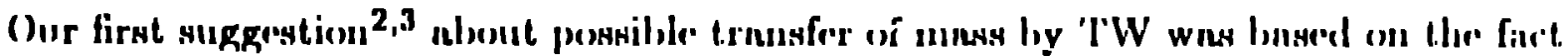
that. the fielels of velocity, concentration and temperaterere are all compled themph the

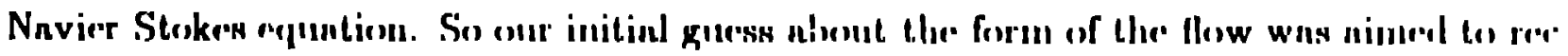

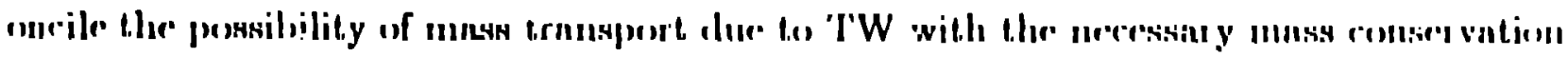

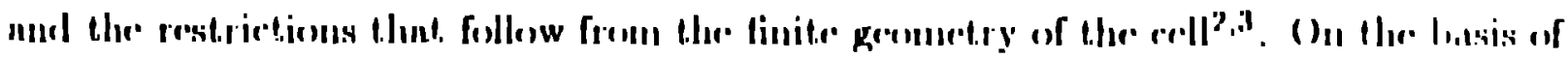


the two-dimengional parabolic shape of the propngating roll pattern in the vicinity cf the Internl walls, we teucled toward a picture of menn drift low, rather than globul circulation with the bark-How returning along the coll sides. We now know that the asodels suggested for the global mass flow were naive and incorrect. However, they have shed light on how convection takes care of itself, and of some different hasic possibilities for the form that a flow in genernl can take.

Since the oscillntory convertion in binary mixtures at the onset lins been found to consist of different types of flow patterns, we were dso intrigued by the possibility that the different stntes and regimes would displny different forms of mnss transport. For exanple, it is hard to imagine mass moving at the finite velocity of the linens counte:propagnting waves when the amplitude of the velocity gors to zero, as is the case for suriall $e\left(r=\frac{\Delta T}{\Delta T}-1\right)$.

Can we then use the differences in mass transport for understanding the unclerlying mechaniams that determine the different oscillntory atntes? Are a global muss flow asid back-fow, compensnting for mnse conservation, described by the anplitude rquation approach? To resulve these questions we undertook a study of the trannport properties of the uscillatory staten trying to identify the motion of mans and the mechanism that manured un nas congervalion in $n$ tinite crll".

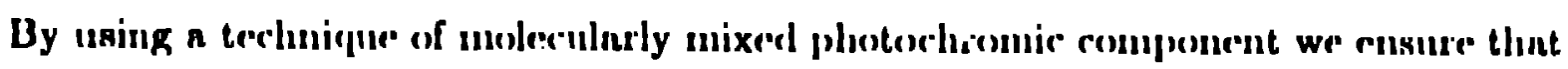
there impuritien alo nest modify the velority fielal. 'This condition requires for passiver

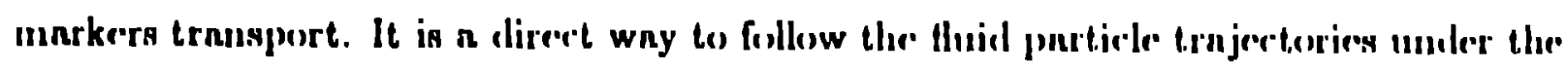
netion of the fluid verlority fielal.

P'roblem of mixing ned stirring" in chestely related to the enestion rnimed in this pen

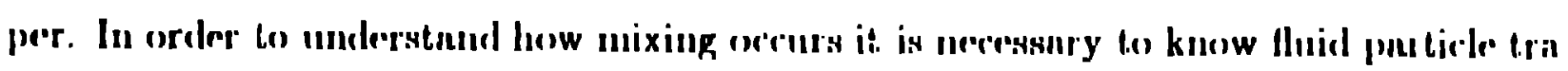

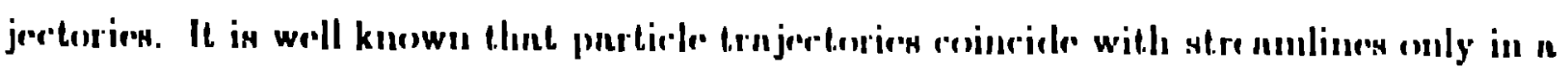

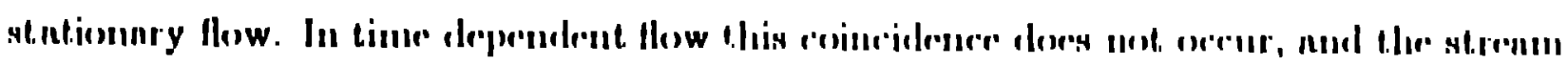

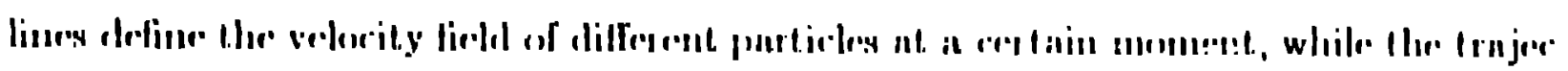


tories define the particle velocities at successive moments. In stationary flows and flows with non-zero mean velocity like TW where flow is stationary in a moving frame, the velocity field as well as the particle trajectories are alwnys well ordered. On the other hand, in time-dependent flows the fluid particle motion mabe extremely complicated. For example, while the motion of three point vortices in an unbounded domain is integrable, particle motion in this flow can be chaolic. We consider in this paper in detail the simplest case of two-dimensional flow when both fluid dymamics and particle motion are integrable. However, evers in this simple case the Lagrangian presentation is very useful to describe the global structure of the particle trajectories and to cluciclate the problem of mixing and transport in a flow of propagating patterns. Our experiments revealed that depending on the ratio of velocity amplitude inside the roll to propagation velocity part of the fluid is trapped and propagates with TW while the rest in accordance with a mass conservation propagates in average in the opposite direction. This global circulation of mass (or mase transport) along the regular trajectories without mixing occurs in a cell infinite in a horizontal direction. In a finite geometry cell this simpie global mas transport is complicated by reflection at lateral boundaries and by corresponding bark flow.

This simple: scenorio can be observed only in a c'ese when existing TW propngntess in ine disertion. Ilowever, in both nonlinear TW states - spatially moduluted TW (confined TW) nud npntially nod trmpornlly modulnted TW (blinking 'IW) - left and right propagnting wnves together with wnves ceflerting from the lateral hounduries exis', simultnneusuly 10-12. It merns thant in n moving frame for one of TW one gets timedependent behavione from the rest of TW. In rase of confined TW an amplitude ratio) of reflecting nud incielent 'I'W is, probul,y, so smatl that resolution of our visunlization

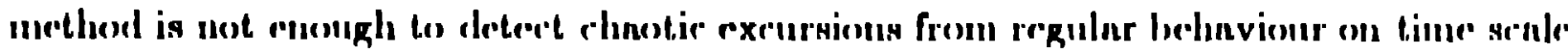

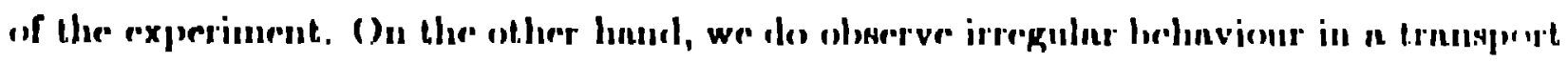

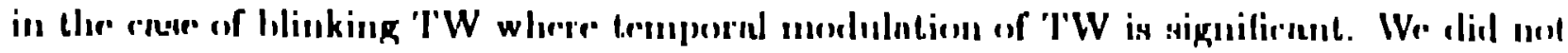


analyse this irregularity due to lack of a model which can transform the chaotic trajectories from a moving to a laboratory frame in order to compare them with the experimental results. Besides the transformation this phenomenon, probably, should be similar to other recently studied examples of cliaotic mixing of fluids in two-dimensional timeperiodic flowg ${ }^{13-14}$. It would be definitely interesting to study the structures produced by this time-dependent flow. It provides useful insight into the mechanism of mixing and transport of fluid flows. And secondly, it provides a visual analogue for chaos in areapreserving mapy in terms of directly observable physical phenomena.

\section{Review of experimental and theoretical resulto}

On the experiusental side very few studies have been conducted on topology of fluid particle trajectories and transport in convective flows. This is especially true for propagative cellular flows, like TW patterns, since these occur near threshold only in few known systems. Work that is close to ours in its experimental appronch, is that of Croquette et. al. ${ }^{15}$. In this work convection of unethanol in a cylindrical cell with asperct ratio $\Gamma=20$ was studied by the use of a photochromir tecluni(ue. A strip of ultra-violet radialion was applied to the cell, rausing coloration of the dye. The subsecpucnt motion of the strip of dye was monitored visually, together with the shodowgraph signal. In this gemmetry the imbilical has a tendency to move off center. It was shown that the distorted pattern is arcompanied by a large scale flow that does not exist for the pantern with the umbilienal in the center. This motion is representative of one type of large scalle motion. 'This is n secondary flow, nud for this type of flow to oceur there must be curvature of the bnsic main flow roll puttern.

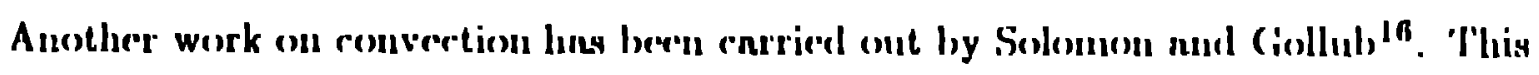
work studied mong transport of nn impurity in stationncy convertion in mn undistorted

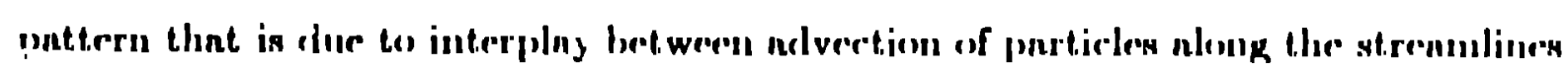

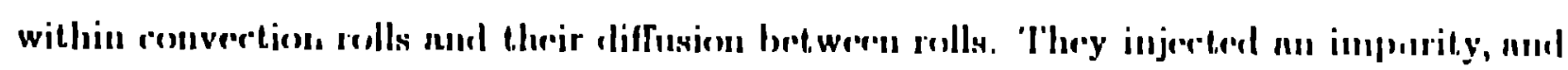

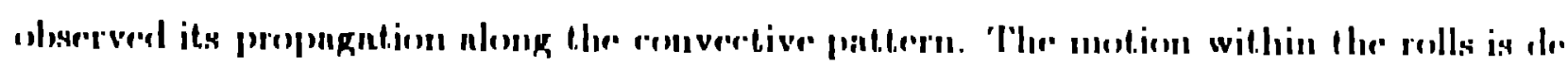


termined by the cou..ction amplitude, and is a fast process. The notion between rolls occurs through diffusion, and depends on the boundary layer that separates two adjacent rolls and on the diffusion constant of the impurity. This flow of the impurity can be: characterized by an effective diffusion constant, that is larger than the original one by a factor proportional to the square root of the Peclet number $p=\frac{v l}{D}$, with $v$ the velocity, $l$ the length scale, and $D$ the diffusion coefficient of the impurity.

Second paper by the saine authors ${ }^{13}$ is devoted to study mixing and transport in a time-dependent convective flow. In the time-periodic regime, tha transport is dominated by advection of tracer particles across roll boundaries. It was shown that in this regime transport is dramatically enhanced due to chaotic advection caused by lateral oscillations of the roll boundaries. The latter conclusion is true for many types of timeperiodic flows. Experimental ${ }^{14}$ and theoretical studics ${ }^{9,17}$ of two-dimensional incompressible time-periodic flows show that dramatical cnhancement of mixing and transport occurs due to crossing of stable and unstable manifolds of hyperbolic points. As the result of it a fluid elemerat becomes stretched and folded so that points originally close become widely separated and others are drawn close together. This process causes mixing of the fluid similar to the chaotic behaviour in dynamical aystems.

Mase tranoport has been otudied by Tam and Swinney ${ }^{18}$ in turbulent CouetteTaylor flow, again by the injection of an impurity and monitoring its transport in lia flow pattern. They also find that the trannport mechanism enn be chnracterized $x$ dif fusion process, and inessure an effective diffusi on constnat that is orders of mangitude lnuger thon $D$.

The importance of the Lagra!:giun reptesentation, i.e. sludying, the "eputi.ns of motion as oppesed to the Eulerinn cleseription, where the equatione for the hedels ane studied, has been emplinsized in the work of Aref'"). 'The: trnjertories of particles inn lon very complex, even if the apuntions for the tielel ure simple. 'This ann lend to chentic

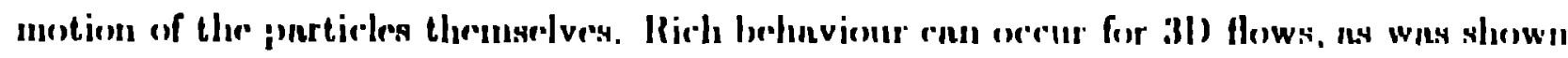


by Feingold et. al. ${ }^{20}$ who used the analogue that exists between Hamiltonian systems and flow streamlines (where mass is the conserved quaniity) to characterize the different Hows possible. In cases of extrcme complexity the motion of a "single" particle that can be nonitored is very valuable, since any finite volume will disintegrate within a short time. These abstract particles are called passive scalars, and are used as a tool for following the flow lines.

An example of the problems involved in using the Eulerian description can be found in the work of Linz et. al. ${ }^{21}$. These authors ask if mass is transferred by looking nt the behaviour of the fields of convection in a few mode truncation of the equntions for convection in a binary mixture. Besides wrong conclusions that mass transportation due to global circulation in TW is negligible and undetectable experimentally unlike transport of concentration, which is the result of a trivial mistake, the authors of Ref.21 used the spatial averaging based on Eulerian deacription. This averaging procedure, perfectly legitimate in a stationary flow, occurs to be incorrect for time-dependent flow or flow with non-zero mean velocity. Here Lagrangian vo. Eulerian description becomes crucial. In a otationary convection with rigid boundaries horizontal component of velocity is oymmetric in a vertical plane. It leads due to mass conservation to symmetric counter-flows in nny vertical plane in the cell. However, it is not the case for TW convection contrary to the result of Ref.21. From Lagrangian presentation one can conclude that two types of particle trajertroies take plare: open nnd closed. Part of a fluid volume trnpped inside srparntrix betwern two types of trajertorien depends on the rntio of velority mmplitude and 'T'V propagation velority. 'This purnmeter, naturnlly, dew's not nlperar in Euleriun description at all 'Then a velocity distribution in the vertical plane in nsymmetric nnd depends on this paraneter. It is obvious that even a total miss flux through any verticnl

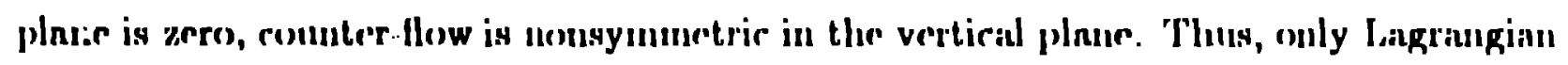

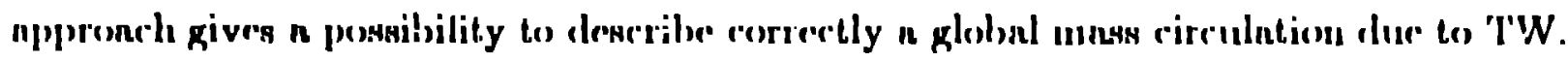

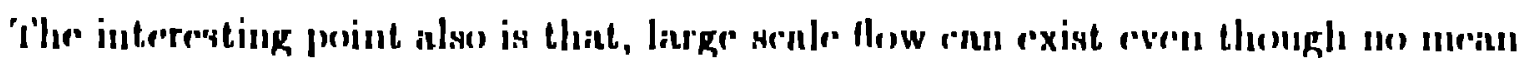


flow exists. In a finite container this means that the convection "takes care" of itself, and we do not have to introduce the back-flow by hand, as it is implicit already in the Lagrangian descrjption. In this case the large scale flow is circulatory, taking mass (in an infinite system) from $-\infty$ to $+\infty$, but also returning an equal annount from $+\infty$ to $-\infty$.

The most relevant work is one that dealt with a one dimensional equation of motion. Knobloch and Weise 22 have shown that a $\mathrm{TW}$ in $1 D$ causes a particle to drift from its original position. This model showed a continuous growth in drift velocity of the particlc as a function of the TW amplitude, saturatisg when it reaches the TW velocity.

The aame authors used ${ }^{23}$ the Lagrangian description to show that for modulated TW cheotic trajectories of particles cen occur. Although they deal with a more complieated situation than ours, we have used the Hamiltonian description which they introduce.

\section{Experimental Methods}

The technique we chose for monitoring particle motion ds that of introducing a strip of dye in the flow, measuring the attenuation of a parallel beam of light as it is passed through the sample. We did this by admixing a small annount of photochromic spiropy$\operatorname{ran}\left(4 \cdot 10^{-4}\right.$ by weight) that is colorless until irradiated by UV light. It then attains a vivid dark color that remains until thermal processes cause the color to fade. This cycle can be repeated many tines with only minimal optical degradation. Our choice of spiropyran was guided by the need to minimize irradiation time while maxinizing the fading time.A characteristic passage time for a roll to propagate along the TW pattern (half the cell length) is 225 sec. Thus the fnding time should be a few times larger. The irradiation time should be kept down to a fow secotuds, which we shall sheow is the chnencteristic time scale for sprencling of the dye within the roll by the rotntional convective motion. 'The spiropyrnu has been supplied by Dr. IR.C. Bertelson, aud is 5bromo-8 methoxy -(6-nitro-1',3',3'-trimethylspiro(2II 1-benzopyrnn-2,2' indolime), solel 
as "Chromadye 2" by Uhroma Chemicals of Dayton, OH. The absorption spectrum at this spiropyran is shown in fig. 1, and is characterized by a broad peak around $572 \mathrm{~nm}$. Thus by using a green filter we were sensitive to the "shadow" of the dye.

This apiropyran has best sensitivity to UV when admixed with aromatic hydrecarbons, while mixing with alcohols decreases its fading rate. With this in mind we chose a benzene - methanol mixture. The beat data for the physical propertiea of a benzene - methanol mixture at $95 \%$ by weight benzene and at $30^{\circ} \mathrm{C}$ found in the literature are $\lambda=i .48 \frac{\mathrm{mW}}{\mathrm{cmK}}, \nu=6.7 \cdot 10^{-3} \frac{\mathrm{cm}^{2}}{\mathrm{sec}}, D=2.3 \cdot 10^{-5} \frac{\mathrm{cm}}{\mathrm{sec}}, \kappa=0.92 \cdot 10^{-3} \frac{\mathrm{cm}^{2}}{\mathrm{sec}}, \rho=0.863 \frac{\mathrm{g}}{\mathrm{cm}^{3}}$, $\beta_{1}=-\frac{1}{\rho} \frac{\partial \rho}{\partial T}=1.2 ? \cdot 10^{-3} K^{-1}, \beta_{2}=\frac{1}{\rho} \frac{\partial \rho}{\partial C}=0.103, k_{T}=-0.16$ and $\Delta T_{c}=2.86 K$ for $d=0.141 \mathrm{~cm}\left(\Delta t_{\exp }=2.85 K\right)$.

The preparation of the sample consiated of mixing typically $4 \cdot 10^{-4}$ by weight of the spiropyran with $50 \mathrm{mg}$ of benzene. This was filtered through filter paper, and then weighed again before methanol was added in the right amount. This ensured that all lcsses due to evaporation during the filtering process could be accounted for and did not reduce the final concentration of benzene in the mixture. In the filtering process any large particles of undissolved photochromic material were removed. Although we could not check this, it is reascnable that these losses more than compensated the loss of ben. zene due to evaporation, so that the concentration of photochromic material in the fluid did not increase in the process.

Our experimental setup is shown in fig. 2, clarifying some of the experimental difficulties. The UV light source we used is a commercial mercury lamp with a fluid filled light guide cord, manufactured by the Dr. Honle Co. of Martinsried, Germany. This light source can output $800 \mathrm{miN}$, with multiple spertra both in the UVA and UVB. The optical components we used were of quartz or sapphire where possible, so that losses through the optical setup are negligible. The main source of losses is in the $1 \mathrm{~mm}$ pin hole used, and in absorption in the $\sim 50 \mathrm{~mm}$ of cooling water that lie in the optical path. We eatimate the amount of UV light to finnlly rearh the cell to be on ihe order 
of $10 \mathrm{~mW}$. Even such an amount could potentially change the convection field drastically. Therefore we checked that the absorption of the UV radiation in the mixture was not enough over the radistion times we used to affect the convection at all. We did this by looking at the amplitude and form of the TW before irradiation, and comparing to its form immediately after.

The setup for the UV radiation (shown in fig. 2) is such that the UV light source is fixed, and the nirror and cylindrical lens are movable. The cylindrical lens can also be rotated to produce a strip in any direction we choose in the cell. During irradiation the mirror protects the camera from the intense radiation and reflcctions. Immediately following the end of the irradiation time the mirror and lens are removed, to clear the view for the camera. The ability to follow irradiation by immediate monitoring sets a limit on the speed of the processes we could study. For irradiation times of 3 seconds, for example, the additional 1-2 seconds needed till the first measurement of the camera can cause some info:mation to be lost. Irradiation times were between 2 and 10 seconds, with 5-7 seconds being typical.

The need to monitor both the shadowgraph and the attenuation caused by the dye are contradictory. The shadowgraph signal is strong away from the cell, and is largest at the focal plane of the lenslets pro luced by the convection rolls. In our case this distance was on the order of $60 \mathrm{~cm}$. To view the motion of the dye, we nust eliminate the effect of the shadowgraph, so we had to focus directly onto the bottom of the cell. In that wny the shadowgraph aignal does not interfere, and the parallel light beam can be used for both measurements. In order to obtain a large image of the $13 \mathrm{~mm}$ cell, we had to bring the camers as close as we could to the cell itself. Thus the compromise was between the size of the image when we followed the dye (spatial resolution) and the resolution in intengity when we monitored the shadowgraph (grey scale resolution). Although this problem could in theory be solved by use of an appropriate zoom lens, we did not find an adequate solution in practice. 
To obtain the maximum from the irrage we had we used averaging in time of the signal. Our camera is an old model made by Hamamatsu, very reliable in response and linearity, but limited to transferring 10 lines per second (compared to the possibility of 25 per second plus the possibility of spatial averaging when using a video frame grabber). We used assembly language routines to minimize computer time while averaging lines. Typical averaging numbers were between 10 and 50, and typical time intervals between measurements were between 3 and 12 seconds.

At a mean temperature of $30^{\circ} \mathrm{C}$ we cun change the sign of $\psi$ by varing a concentration. This resolves a controversy that existed about the Soret coefficient for this mixture ${ }^{24}$. The controversy stems from the fact that the region of oscillatory convection is very small, so that techniques for determining the sign of $\psi$ by looking for oscillatory convection can be misleading. At benzene concentrations of $10 \%$ and $50 \%$ by weight square stationary patterns typical of positive $\psi$ were observed. At $95 \%$ by weight benzene an inverse bifurcation leads to finite amplitude TW via CPW, and $\psi$ is negative. The TW branch exists in a narrow range of $\sim 20 \mathrm{mK}$ (not including hysteretic regime) for a cell of height $1.47 \mathrm{~mm}$ and aspect ratio 1:4:12.25. Our estimates based on data from the literature give $\psi=-0.045$. We can compare this with the value $\psi=-0.044$ deduced from the experimental value for the neutral frequency, $\omega_{0}=4.4$ using the dependence ${ }^{25}$

$$
\omega_{0}=\frac{\kappa}{d^{2}}\left(\frac{3 \pi^{2}}{2} a\right) \sqrt{\frac{-\psi}{1+\psi+P^{-1}}}
$$

with $\mathrm{a}=1.43$. We have observed in this mixture confined $\mathrm{TW}$ states ${ }^{2,4-7}$ in which convection existo only in part of the cell. For imall enough step size from conduction, the first state was a temporally and spatially modulated one (a "blinking state") ${ }^{26}$. The confined state always appeared high on the TW branch. The spatial pattern of the blinking state consists of alternation between left and right $\mathrm{TW}$, both being modulated in space, with periods of coexistence in mid-cycle. The fart that the TW state that fills the rell was not observed may be due to the narrow range of the TW branch, or to the 
amall thermal conductivity of the mixture when compared to the cell boundrries ${ }^{27}$. Thun, the experimental data we present on mass transport in the nonlinear TW state is that of the confined TW and the blinking state patterns.

What we actuslly measure is not concentration but attenuation, and we must take this into account. The tranomitted intenoity is given by

$$
I(x)=I_{0} \int e^{\frac{-C(u)}{10}} d z
$$

where $I(x)$ is the measured intensity at point $x$ ( $x$ is the direction along the cell), $I_{0}$ the initial intersity, $C(z)$ the concentration of excited photochromic dye at point $z$ along the height of the cell ( $y$ is the direction acrose the cell), and $z_{0}$ the attenuation length that characterizes the abaorption of light by the dye (we assume that the green filter allows only a omell bandwidth to pass). The integral should be taken along the full optical path, i.e. through the cell depth and back. If we want to use this relation in a quantitative way we must make come asoumptions on the form of $C(z)$. This is usually done by waming a uniform distributicn of the dye along the cell13,16,18. An we shall wee presently this is not 80 in our case. However, we note that the actual attenuation is amall enough to that plotting the attenuation or its logarithm is cosentially the same.

\section{Experimental Result.}

\section{Conduction}

In ff. 3 we whow the result of irradiating a single line acroas the cell, at a dintance from the cell wall which is typical of the experiments on the convective otnte. We nee that the initial shape is cloas to a gausninn one. This is due to the optienl actup, and in ronvenient for our analysin. The FWHM of the gnusainu is nixout $1.2 \mathrm{~mm}$, slightly Irson than the size of $n$ convertion roll, $1.5 \mathrm{~mm}$. The evolution in tiune is thent of $\mathrm{n}$ ofereny in amplitude and widening of the knussinn. We can model this by $C(x, t)=A(t)$. Grussinen( $r, t)$, whore $A(t)=r^{-1}$ :

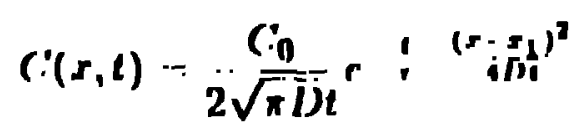


with $t$ the time, $\tau$ the characteristic decay time for the thermal fading of the photochromic, and $x_{1}$ the center of the gaussian. We have 2 parameters to fit every line of fig. $3, A(t)$ and $\sigma^{2}(=2 D t)$ of the gaussian. Fig. 4 shows a representative measurement. The dots are data, and the curve is a fit using the above function. We sce tisat the model gives a good fit. This quality of the fit is characteristic of all these measurements.

In figs. 5 and 6 we show she results of fitting for $D$ and $T$. Fig. 5 shows the decay prefactor as a function of time. The dots are experimental points, and the curve is a best fit to an exponential behaviour. We see a relatively long tranjient, after which the data fit an exponential decny with time constant $\tau=490 \pm 70$ seconds. The fact that our initial profile was actually gausoian eliminates a common cause for transients. The transient we see may be due to processes that we cannot view, i.e. in the unscen direction, the depth of the cell. The time scale of the 'ransient is about 200 seconds. This is approximately the time scale for diffusion of the dye on $n$ length on the order of the cell cepth. We conjecture that this trangient is largely due to a diffusion process in which the dyc diffuses downwards, into the depth of the cell, until the profile in the $z$ direction homogenizea. During this period the decay of concentration is lesy than expected by the simple model, since the diffusion in the $z$ dirertion comen iastead of diffusion in the: $r$ direction. The renson for an inhomopgeneity in the $z$ direction is that our irraclintions enters the anuple from the top. As it penetrates the Huid, it :xriter the photochroinic

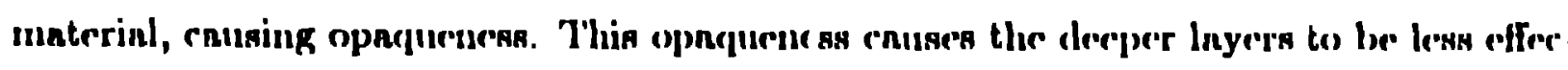
tively excited, with the finnl ontronac that the concentration of lye dererenses with the depth. We shall present evidenere for the depth dependenere of the dye comerentration be.

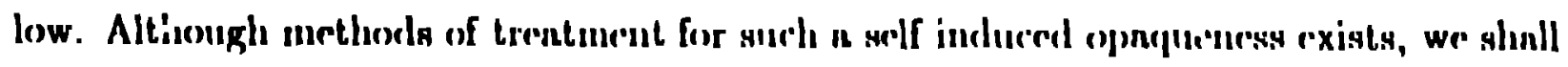
not make an atcempt al charueterizing the z dependencer of the concentention. Where possible (i.r. no qunntitutive dotsi is taken from the mupliturless), we make use of the sig. nal fron the intensity itself, mether thun make clnims nhent the concentention. 
Fig. 6 shows the fit for $D$, plotting the variance $\sigma^{2}$ of the gaussian versus $2 t$. Again, the dots are experimental points, while the curve is a linear fit, yielding $D=(1.0 \pm$ $0.2) \cdot 10^{-5} \frac{\mathrm{cm}^{2}}{s e c}$. The transient is not as noticsable here, but is still apparent. Here the effect is to reduce the diffusion in the $x$ direction until the profile in the $z$ direction is homogenized. The reduced sensitivity to the transient may due to the linear behaviour. At large time scales the width of the gaussian along with smail amplitude cause scatter round the linear fit.

\section{Stationary convection}

The state following the oscillatory branch is one of stationary convection, similar to that in pure quids. In thio section we present results on mase transport in this regime. For figo. $7-9 e=0.02$ still quite close to onset. The results presented are mainly qualitative, aimed at comparison with the following section on mass transport in the oscillatory regime. We can, ho. ever, obtain some interesting insight as to what can be observed with the photochromic technique.

Fig. 7 shows the result of irradinting a strip across the cell at the typical $\frac{1}{3}$ of the rell length. The irradiation time is 5 seconds, and we sre that the initial gau ian shnpe is distorted already by the time of our first mensurement. The gnussinu spans two rolls. with a tendency to the one at the right. Within $2-3$ messurement times (time: betwen menturements is 5 .occonds) the dye has homogenized over the size of the roll. This in-

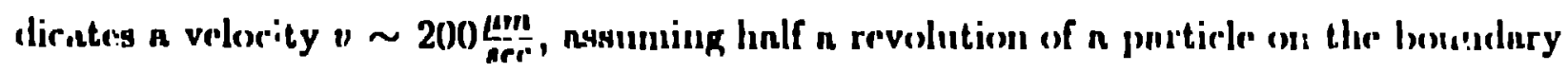
"f the roll for homegenizing the dye over the roll in the re direction. 'The two rolls that. nre initially rulinted settle to a constint simplitucue of clye, thut derengs at the rinte men.

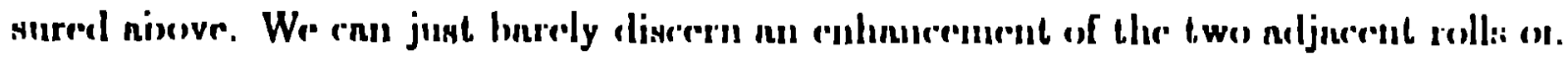

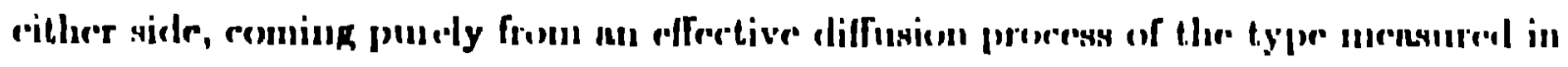

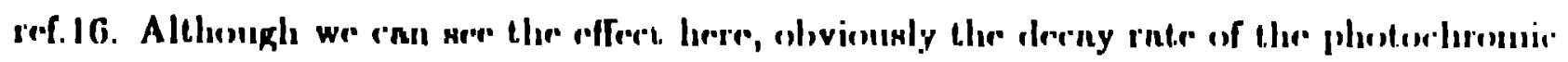

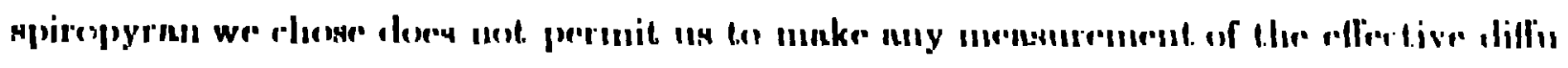
siom rorellicient. 
To follow the process of homogenization within the rolls by the convection we do two things. First, go down to 3 seconds exposure and messurement intervals. Second, we irradiale a atrip at the side of the cell, where the boundary of the wall has a damping effect on the amplitude of the convection. We see in fig. 8 for such $n$ test thnt the amplitudes of the roll next to the wall takes about 2-2.25 times longer to homogenize than does the adjacent roll (whose time is similar to that in fig. 7 ). The estimate for the velocity of the roll near the boundary is $v=90 \frac{\mathrm{m}}{\mathrm{sec}}$.

Finally, we show in fig. $\theta$ the reault of irradiating a otrip along the cell, i.e. along the $x$ direction. The aignal, although homogenous at the onset. is seen to be highly modulated, at the characteriatic wavelength of the convection (2 rolla). We underatand this as stemuning from an initial inhomogeneity in the $z$ direction. After a quarter of a cycle the high concentration from the top will go in each roll to one side, while the bettion will rotate to the opposite side. The rolla are paired so that this effect is reinforced, encin pair enhancing or decreasing together the intengity of the boundary betwren them. We can nee that a quarter of a cyrle occurn faster than our first meanurement, giving ngnin

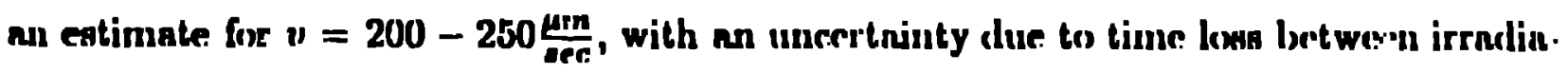
tion and the first mensurenent, as explained ulxove. This result is the one wr rely on in our nunlynis of the transiente in the dereny of the gnumaiuss in the suection alouve.

Another obaservation, not shown here, was that although scromelary motion in the $y$ dirertion mny be exporeted (dure to 31) effects in the flow), these motions were mot nppenr ent within onr remolution. An initial strip nlong the cerll (s direction) whowed no sign of

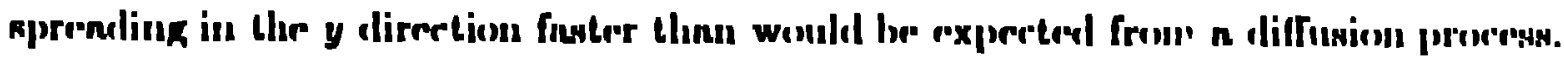

\section{()arrillntory (ionveretion}

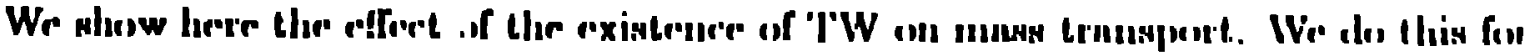
the contined 'IW nentr, then briefly for the blinking ntnter und ('l' IV.

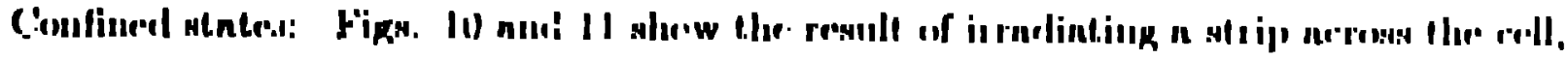

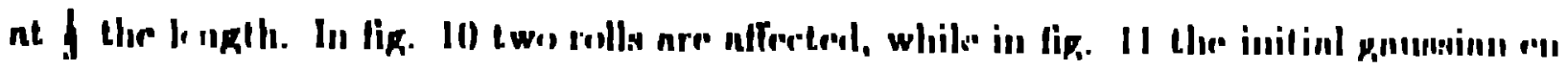


closed only one roll. Mass is definitely transferred in the TW dirsction, at the TW velocity, in a periodic structure with the size of the convection rolls. The existence of a flow in the opposite direction is evident. This is the backflow needed to maintain maso conservation. The motion of the part that moves with the TW is scen to be rather straightforward along the $1 \mathrm{D}$ line depicted. The roll detaches from the patch of dye, and propagates smoothly and continuously till the edge of the cell. The task of extracting the velocity of the TW from these figures is complicated by the existence of chnnges in wavenumber (see fig. 13a below). Since the frequency is constant over the cell, the velocity varies over the TW pattern. We cun take the signal from the slindowgraph to obtain the frequency, multiplying by the critical wavelength to obtrin an estimate. This is in prattice a lower bound on the velocity.

To obtain further information on the bnckfow we irradiate an initinl strip lorated just next to the short wall of the cell.

This is shown in fig. 12. The backflow nppears in a discontinuous fashion, with strips nppenring at distnures corresponding to multiples of the roll size. This discreteuess can only be: explnined as a lockal concentration of c.ye nt fixed points on the roll strurture nlong the cell. 'The motion enn best. be describerl as follows: n prenk of iuten

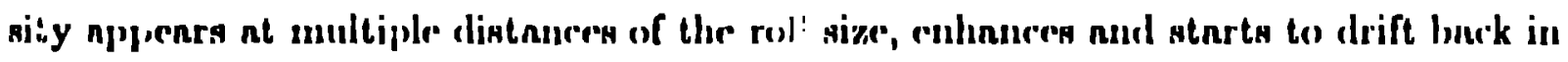
the dirertion of mud at the veleceity of the 'IW iterelf. 'I'hus we sere that the huek flew is restrieted by the frnme of the traveling rolls. Ther snunll number of convertion rolls limit the necurney in determining the buekflow front velocity in tig 12. ()ur estimnte is

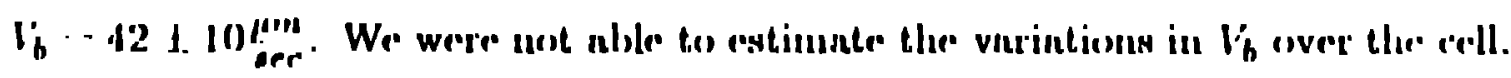

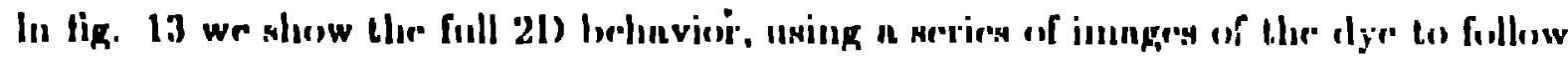

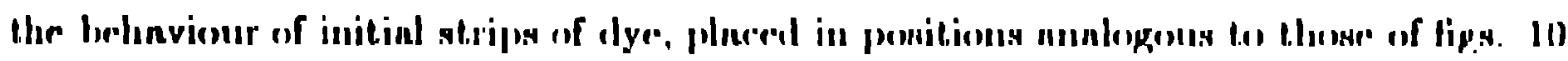

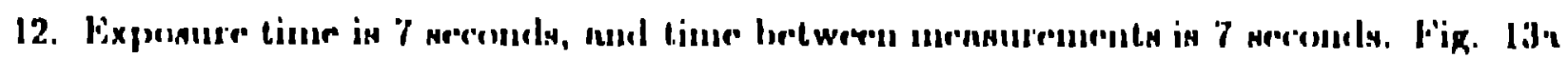

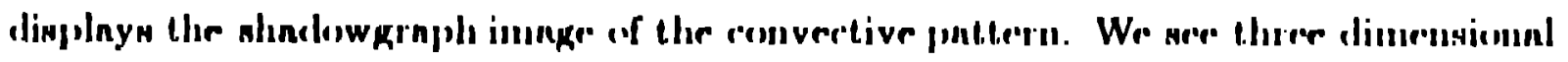

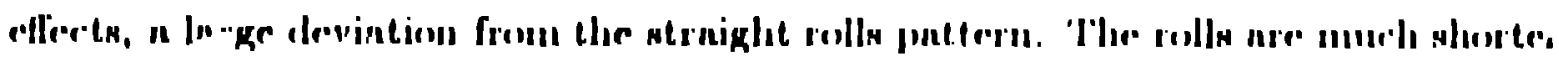


near the edge of the cell, occupying as little as one half of the width of the cell. While a boundary layer is expected to exist, the mensured size of the lnyer exreeds nuly theroritical eatimate.

In fg. 13 b) and c) we show the npreading secluence for the two different initinl possitions of the dye. In the TW direction the form of the dye front is poraloolie nt the beginning, then changen to the form of the roll structure shown in Fig. 13n, filling nhout lialf the cell width. The barkfliw aloo has a parabolie profile along the width of the crll, and seems to maintain it.

In fig. 14 we show the nualogous situation to that of fig. 9, irrolinting nlong the cell. In this case we sere that the nonuniformity chused by an inhomogenous profile in the $z$ direction is alos found here. However, the mixirg mechanism thext existed in the stationney regime doses not work here, nud the modulntion of the profile is maintnined in time. We shall nee bedow that this enn be linked to the behaviour of the besumelarion of the rolls.

'Lruporally nul mpntinlly modulntenl 'IW (blinking stnke): In fig. 15 wo show the

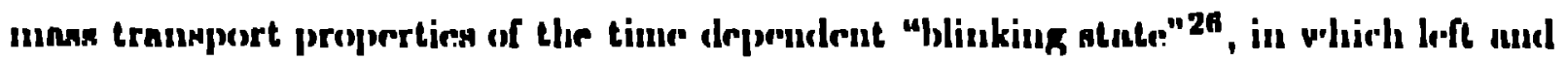

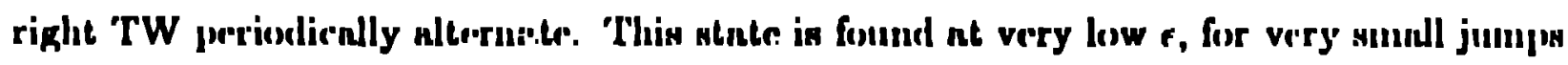
from ronchurtion, na n prerurmer to the ronfined stnirs. The two oppessite 'ITV nre mod uluted on a slow time nenle, but with n phne difference betwern them. At lirst one 'IV

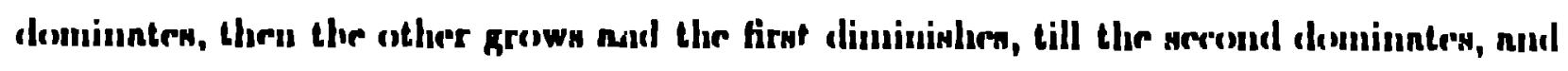

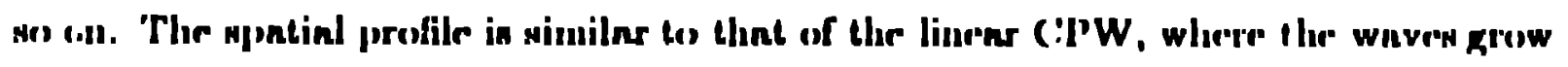
an they propagnte, but with nomlinenr anturation apponrent. 'The time speretrum of the

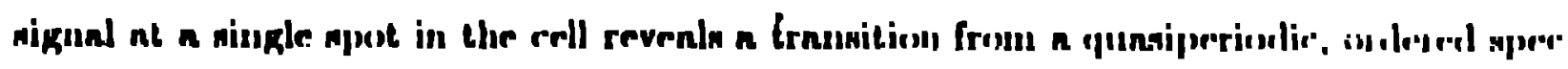
truun ne low e, to a many pronkrel elimurclerred our.

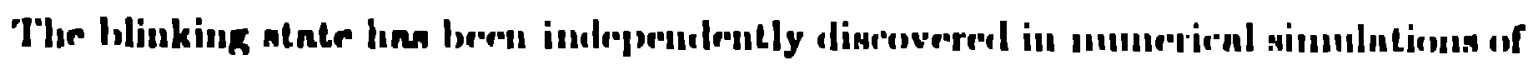

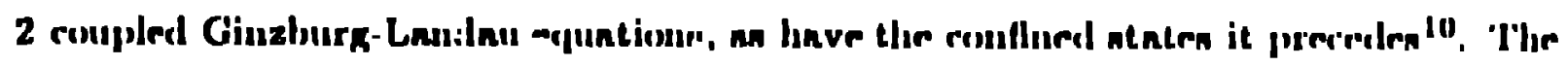

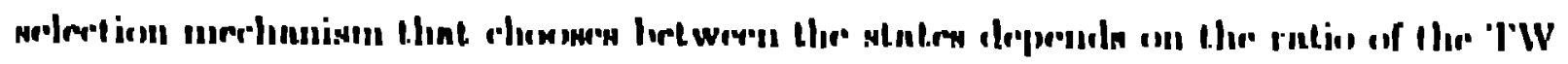


propagation velocity $s$ to the local growth rate $T^{-1}$ on characteristic local scale where $s$ is the group velocity and $\xi=\xi_{0} \epsilon^{-1 / 2}$ and $\tau=\tau_{0} \epsilon^{-1}$ are the spatial and tomporal characteristic scales. This selection is relnted to the transition from converted to alssolute instability conditions, which occurs at $n$ defined value of this ratio.

Fig 15a shows a right TW, and we see that at the opposite side no mass motion is apparent. We note 1 at the division of left and right TW occurs at the center of the cell, emphasizing that the nonlinear profile has a rapid variation in midecll. Fig. 15lo shows a time in which both TW have comparable anplitucie, and both are sern to transfer mass (this coexistence is for a brief period of time). We have also measured brief occurrences at which both TW were nt $n$ minimum, nud no mass wns transferred in either direction. Finally, in fig. 15e the left TW dominates, and in the right sicle of the cell no mass is transferred. It is impressive that the large scale motion con be initiuled and stopped within the short time scales that separate periocls of dominntion (order of $0.1 \tau_{h}$ horizon tal diffusion time)

We would like to posint out here that spentio temporal plots of dye intensity profiles in the blinking state exhibit lews regulne behnviour than the corresponding plots (Fig. 10. 12) for confined TW. A possible reuson for this disorder is a temporal modulntion of TW. As we alrendy mentioned in the Introduction the time-periodie perturbations anuse

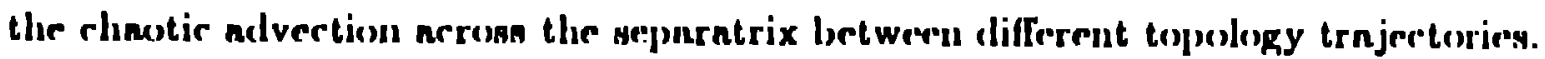

It in not clear wint kind of behnviour mhould be observed then in $n$ Inborntory freme. in which the data are presented. It in also pomaible that much finter mixing (honocgenizntion) obnerved on Fig.15 than on Fign. 10.12 is the result of the chinetic ndverelion. 'Thin proint nerelu further experimentul ancl theroretienl studies.

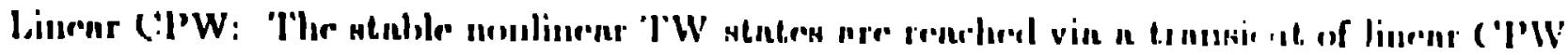

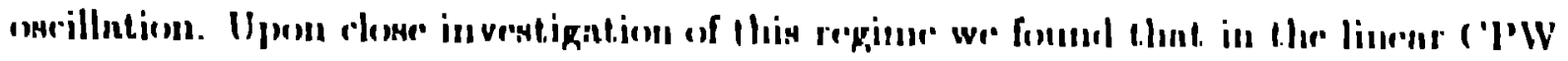

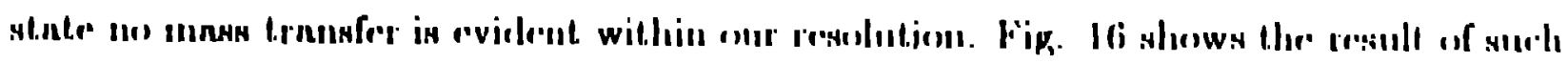

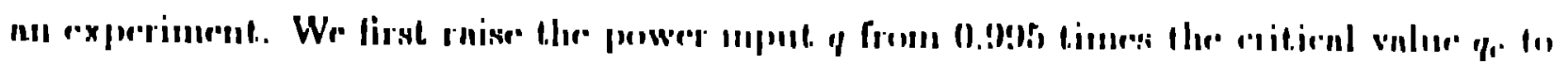


$q=1.0015 q_{c}$ at $t=0$. A linear CPW transient is discernible after about 40 min. Fig. 26a shows the shadowgraph signal beginning at $t=52$ nin, with two counterpropagating waves filling the cell. Their velocity is $V_{p}=84 \frac{\mathrm{um}}{\text { sec }}$. We then irradiated two strips of UV light at each side of the cell for a period of $6 \mathrm{sec}$, and monitored how they spread. No mass motion is apparent until the nonlinear TW state is reached, and this is shown in Fig. 16b. The first lines (beginning at $t=65 \mathrm{~min}$ ) show no signs of mass propagation. Towards the top of Fig.16b, at $t \approx 66.5 \mathrm{~min}$, the -ight strip of dye undergoes a breakdown, and mass propagation begins. The left strip remains untouched, slowly fading, ns a nonlinear TW state is reached, with convection only in the right hand sicle of the cell. This is the stage where the linear CPW develops into nonlinear TW. Thus the transition from linear CPW to nonlinear TW is tied to a transition from no mnss propagntion to large scale flow.

W. have checked that the amplitude of the CPW before the transition in not markedly different from that of the TW after the transition, (while a jump in the TW frequency does occur). This indicates to our mind either a critical transitior, or that the two states are governed by different mechanisms.

\section{Theoretical Model}

To model this behaviour of the convective flow in confined TW state we linve used n simple form of 'TW for the nuplitude of convertien, that nswumes the existence of only

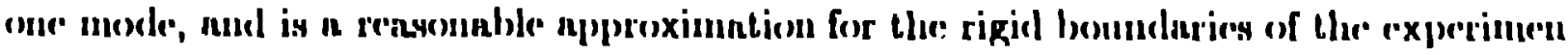
lnl cell:

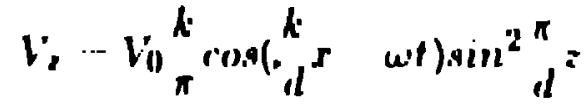

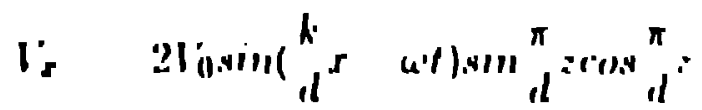

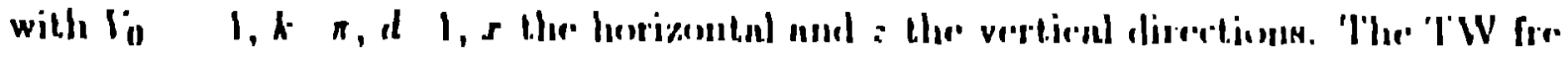
rimeney $\omega$ is $n$ phomeneter wor vary.

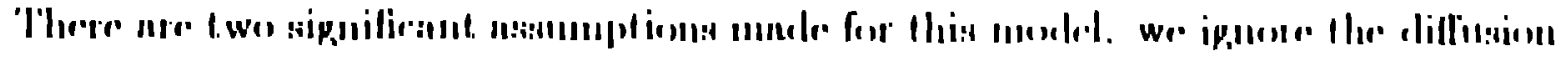


effects and consider that only one TW existing in the confued state. First assumption is based on the fact that the Peclet number $p$ is typically mucli larger than 1 (of order 100), so that diffusive processes are really negligible in comparison with the flow effects. Second assumption is less obvious since as known 10-12 a spatial modulation of TW is the result of interaction of left and right-propagating waves and waves reflected from lateral boundaries. Probably, in the case considered the nmplitude ratio of left and rightpropagating waves in a right part of the cell is small enough that we did not observe cffects due to modulation by left-propagating wave. These equations were integrated in tirue using a standard Runge-Kutta algorithm (Fig. 17a).

The flow is seen to separate into two distinct regions. One part moves with the TW while the second flows on the boundaries of the roll, with an average motion in the direction opposite to the TW propagation. This second part is the backflow. We can now associate the discrete peaks appearing in the backflow in Figs. 10-12 with the arrival of the backflow front at a boundary between rolls, where optical absorption is large due to our viewing the cell from the top. This is exemplified in Fig. 17b which depicts the rquivnlent of our mensuring technique, integrnting the dyed particle density ulong $z$.

If we vary our parnizeter $\omega$, we sere that the flow chankes drastienlly. Fig, 18n-b show the effect of incremsing the 'TW velocity. The volume thes move with the 'TW de. crenses, and the backflow velocity falle below the 'TW velocity. Furileer decrense of the freppenery, such that the 'TW mover al a verlocity fauter then $V_{0}$, is shown in figs. 19nb. At this value the molion with the 'TW areses, nul the motion is nimost symmetric in

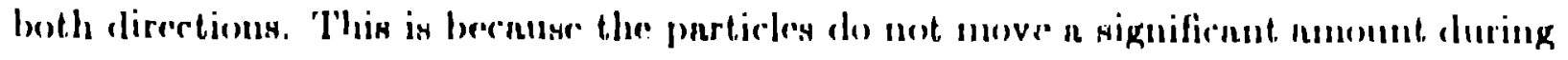

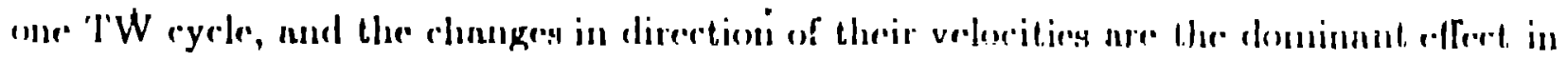
Hetermining the molion.

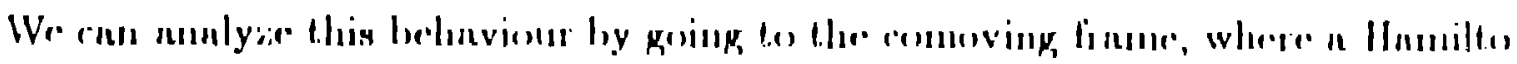

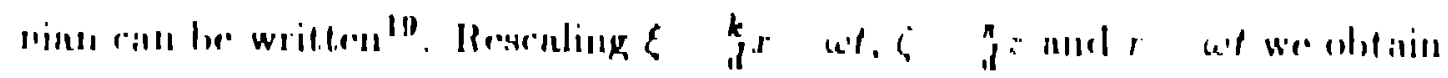

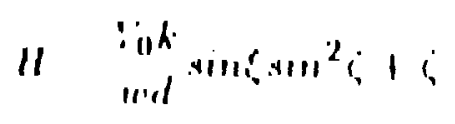


We see that the combination of parameters $R=: \frac{V_{0} k}{w d}=\frac{V_{0}}{\frac{V}{T w}}$ is more appropriate for describing the system than just the frequency $\omega$. For $I_{i}>1$ this Hami'tonian has a separatrix that divides $(\xi, \zeta)$ space into closed and open orbits. Thus it is the open orbits that comprise the backflow, while the closer unes define a now "reducad" coinoving roll. We can estimate the experimental valı of $R=\frac{V_{0} l:}{w d}$ by measuring the backflow and TW velocities. The data of Fig. $2 \mathrm{~b}$ at a $\mathrm{TW}$ velocity of $\approx 40 \mathrm{\mu m}$ can be described by $R \approx 2$, giving $V_{0} \approx 80 \frac{\mu m}{s e c}$. An interesting feature of this Hamiltonian is the existence of a transition in the topology of the trajectories. As we decrease $\Omega$ the separatrix orbit slurinks, till at $R=1$ it disappears. This is the point we associate with the transition from fig. 18 to fig. 19, when mass propagation with the TW velocity ceases to exist. Fig. 20 shows this transition in the streamlines of $H$ for different values of the parameter $R$.

We can find the origin of this transition in the fixed point behaviour of $H$. If we iook at the $[0,1] \times[0,1]$ square these are t!e points $\xi=\frac{\pi}{2}, \zeta==\frac{1}{2} \arcsin \left(-\frac{1}{n}\right)$ (for the $(-1,0] \times[0,1]$ square the relations are similar but reflected round $\left.\zeta=\frac{\pi}{2}\right)$. The vilue of $H$ at the two fixed points is

$$
H_{\int p}=\frac{R}{2}\left(1 \mp \sqrt{1-\frac{1}{R^{2}}}\right)+\frac{1}{2} \arcsin \left(-\frac{1}{R}\right)
$$

For $R>1$ these fixed points exist, while for $R<1$ they are undefined. Looking ablong the lime $\xi=\frac{\pi}{2}$ these points nee extremen of $I I$. () ne of these fixed poitits (the maximum of $I I)$ describers the center of the comoving well, while the other sits on the sepuratrix (nctunlly a hemoclinic orbit). In the limit $n$, w the fixed point nt the center of the

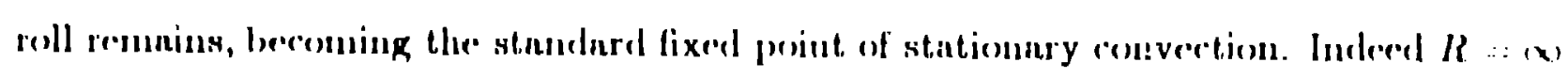

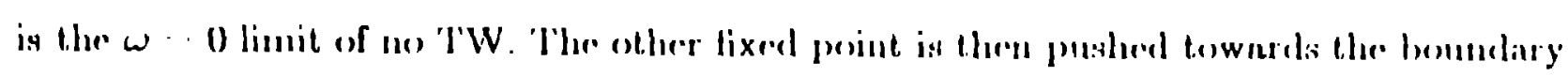
5 $\pi$, which in the comeving frane is alwnys moving at velority $l_{s}-1$. In the linit

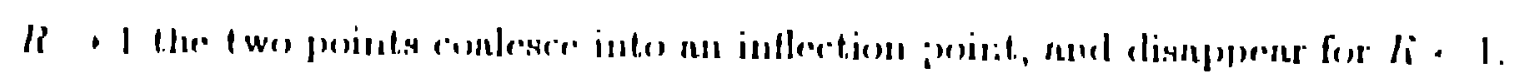

VI. I)iacussiun 
The main objective of this work has been to identify the processes of mass transfer by TW. We have found that for nonlinear TW a "reduced" comov"ig roll carries mass at the TW velocity. The rest of the fluid, in the area that surrounds the reduced rolls, carries mass back, taking care of mass conservation. Both of these are reproduced from a simple model for the TW. This result reinforces the ideas of the amplitude equation approach, that information on the velocity can be obtained from information on the temperature (and concentration).

A step beyond this is the differentiation between linear and nonlinear regimes based on mass transport. We have found a transition to mass transport that coincides with the onset of the nonlinear state. Mass transport can obviously perturb the concentration field, leading to the breaking of the linear profile. In the linear regine uny given fluid volume is executing oscillatory motion round its equilibrium point, and the concentration profile to be a linear. Once mass begins to move with the TW the concentration stratification may be disturbed by a varying degree. This change would lead away from the linear regime, into the various nonlinear TW states. Such an effect would dominate over any boundary layer process" (that also tends to distort the linear concentration profile). since this depend on changes in $V_{0}$, which are small for the ronfined and blinking states (the exact change depends on the final state and on 6 ).

It is interesting that the blinking stnte, although only weakly nonlinear, is robust under this distortion of the linear concentration profile. It would be interesting to sim ulate numerically (perhnps for the exact solutions) the behaviour of the concentration field under the various types of flow.

The difference between the regimes is seren nlso when wr look nt possible models for the system. For the trauslationnl symmetry of the TW we can go lo the comoving frame, removing the explicit time dependence from the requntions of metion. 'This lends to a time independent Hamilteminn. In the cose of coexisting left nut right lWW such n

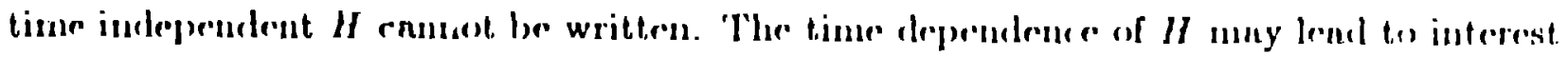


ing new phenomena, related to chaotic mixing.

A few questions are interesting and as yet remain unanswered. Although the model we use is a crude one, it gives a prediction for the $R$ dependence seen by pertorming a scan along the TW branch. Measuring the main and backflow velocities, for example, would enable checking the $R$ dependence of the relative size of the two oppositely moving volumes.

Another open question concerns the mixing region where main and back flows join at the edges of the convection pattern. Obviously fluid transported to the edge of the cell with the TW must find its way into the backflow, be transported to the other edge of the convection pattern, and there be reinjected into the main flow to maintain the cycle. The way in which this is done could reveal much about the role of the boundaries. The work done by Cross ${ }^{10}$ has shown the importance of the boundaries and the reflection there, and it would be interesting to assess the effect of a mixing layer on these. The model considered does not incorporate this mixing. We did not model also 3D effects in a mass transport and did not find an explanation for 3D siructure and parabolic shape of the fronts observed in the experiment.

Thus the distinct feature of nonlinear TW states is the existence of the mass transport with propagation velocity of $T W^{\prime}$. From our experiments ${ }^{20}$ we know depending that on a stepsize in a temperature difference from the convection threshold different TW states can be reached at different values of the amplitude. It means that transition from linear to a nonlinear state occurs at different values of the parameter $R$ which determines the transition in a topology of the particle trajectories. Therefore we can conclude that the onset of the mass transport accompanies the transition from the linear to the nonlinear oscillatory state, but is not the primary reason for the instability. The nbsence: of mass transport in the linear TW is perhaps related to the fact that the CPW are basically a form of standing waves. 


\section{References}

1. R.W. Walden, P. Kolodner, P. Passner, C.M. Surko, Phys. Rev. Lett. 55, 496 (1985).

2. V.Steinberg and E. Moses in "Patterns, Defects and Microstructures in Nonequilibrum Systems", NATO ASI series, ed. D. Walgraef (Martinus Nijhoff Publ. 1987). p.30y.

3. E. Moses and V. Steinberg, Phys. Rev. A34, 693 (1986).

4. E. Moses, J. Fineberg, V. Steinberg, Phys. Rev. A35, 2757 (1987).

5. V. Steinberg, E. Moses, J. Fineberg, Nucl. Phys. (Proc. Suppl.) B2, 109 (1987).

6. R. Heinrichs, G. Ahlers, D.S. Cannell, Phys. Rev. A35, 2761 (:987).

7. G. Ahlers, D.S.Cannell, R. Heinrichs, Nucl. Phys. (Proc. Suppl.) B2, 77 (1987).

8. E. Moses and V. Steinberg, Phys. Rev. Lett. 60, 2030 (1988).

9. See e.g. S. Wiggins, Nature 333, 395 (1988).

10. M.C. Cross, Phys. Rev. Lett. 57, 2935 (1987), and to be published.

11. P. Kolodner, C.M. Surko, H. Wiliams, these proceedings.

12. V. Croquette, $\mathrm{H}$. Williams, these proceedings.

13. T.H. Solomon asd J.P. Gollub, to be published.

14. J.M. Ottino et al, Nature 333, 419 (1988), and references cited therein.

15. V. Croquette, P. Le Gal, A. Pocheau, R. Guglielmetii, Europhys. Lett. 1, 393 (1986).

16. T.H. Solomon and J.P. Gollub, Phys. Fluids 31, 1372 (1088).

17. V. Rom-Kedar, Ph.D. thesis, Caltech, 1988, unpublished.

18. W.Y. Tam and H.L. Swinney, Phys: Rev, A36, 1374 (1987).

19. H. Aref, J. Fluid Mech. 143, 1 (1984).

20. M. Feingold, L.P. Kadmoff, O. Piro, to be published.

21. S.J. Linz and M. Luicke, in Propagation in Nonerquilibrium Systems, col. J.lS. Wesfreid, H.R. Brnud, P. Manneville, (i. Alhinet und N. Borenrn, Springer Prox. 
Phys. 30 (1988) and S.J. Linz, M. Lücke, H.W. Müller and F. Nederländer, preprint.

22. E. Knobloch and J.B. Weiss, in "The Internal Solar Angular Velocity", ed B.R. Durney and S. Sofia, (Reidel, 1987).

23. E. Knobloch and J.B. Weiss, Phys. Rev. A36, 1522 (1987).

24. J.C. Legros, P. Goemaere, J.K. Platten, Phys. Rev. A32, 1903 (1985) and teferences therein.

25. D.T. F. Hurle and E. Jakeman, J. Fluid, Mech. 47, 667 (1071).

26. J. Fineberg, F. Moses, V. Steinberg, Phys. Rev. Lett. 61, 938 (1988).

P. Kolodner, C. Surko, Phys. Rev. Lett. 61, 942 (1988).

27. J. Fineberg, E. Moses and V. Steinberg, to be published Phys. Rev. A Rapid Comm. 


\section{Figure Captions}

Fig. 1: Absorption spectrum of the photochromic compound used, in a mixture of $95 \%$ wt. benzene and $5 \%$ wt. methanol.

Fig. 2: Schematic diagram of the experimental setup.

Fig. 3: Logarithm of the attenuation profiles along the cell show the diffusion and decay of the dye in the conductiv state. Time progresses upwards, and the interval between profiles is 12 sec. Initial irradiation lasted $10 \mathrm{sec}$.

Fig. 4: Single profile of the dye distribution along the cell. Points are data, and the curve is a best fit to the model. Taken at $t=300$ seconds.

Fig. 5: Decay prefactor versus time for the profiles obtained from fig. 3. Points are values from the individual fits, and the curve is a best fit to an exponential behaviour.

Fig. 6: Variance of the gaussian versus $2 \cdot t$ for the profiles obtained from fig. 2 . Points are values from the individual fits, and the curve is a best fit to a inear behaviour.

Fig. 7: Attenuation profiles along the cell show the spreading of the dye from a strip near midcell in the stationary convection state. $\epsilon \approx 0.02$. Time progresses upwards, and the interval between profiles is $5 \mathrm{sec}$.

Fig. 8 Attenuation profiles along the cell show the spreading of the dye from a strip near the edge of the cell in the same state as fig. 7. Time progresses upwards, and the interval between profiles is 3 sece.

Fig. 9: Attenuation profiles across the cell show the modulation of an initially ho. mogenous strip of dye along the cell in the same state as fig. 7 . Time pro gresses upwards, and the interval between profiles is 3 see.

Fig. 10: Attenuation protiles along the cell in a confined stute in the hysterente region of the TW branch with $\frac{q}{4}-0.998$, after initinl UV irrndiation nen mid coll Time pregressess upwards, and the interval bertwern potiles is $i$ sere. 
Fig. 11: Attenuation profiles along the cell in a confined state in a clifferent ceil $(d=$ 1.41 ) in the confined TW state with $\epsilon=0.007$, nfter initinl UV irradiation near mid-cell. 'Time progresses upwards, and the interval between profiles is 4 sec.

Fig. 12: As in fig. 10, but with initial irradiation near edg" of cell.

Fig. 13: a) Shadowgraph image of the confined state at $\frac{q}{q_{c}}=1.008$.

b) Consecutive images of the dye show its propagation in a confined state with $\frac{q}{q_{c}}=1.008$, for an initial UV irradiation near the center of the cell.

c) As in b), but for initial irradiation near the edge of the cell.

Solid frame inclicates the borders of the experimental cell.

Fig. 14: Attenuation prot.les across the cell show the modulation of an initinlly homogenous strip of dye along the cell in the same state as fig. 10. Time progresses upwards, and the interval between profiles is 7 sec.

Fig. 15: Attenuation profiles for a blinking stale. $e=0.0027$. a) Right TW.

b) convection in both parts of cell. e) Laft TW. Time proggessess upwnrds, and the interval betwern profiles is 5 sece.

Fig. 16: a) Shadowgraph intensity profiles along the cell during the (:PW transient. Time progresses upwards, and the interval between profiles is 15 sere.

b) Attenuation profiles along the crell during CPW nud their trmusition to TW nfter initial UV irralintion of strips in both sidess of the cell. 'T'ime pro gresses upwnds, nud the interval between profiles is 4 isere.

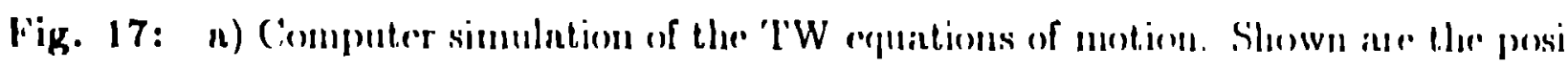
lions of 2048 phrticles in the convertion cell nt constant time intervals, nftere

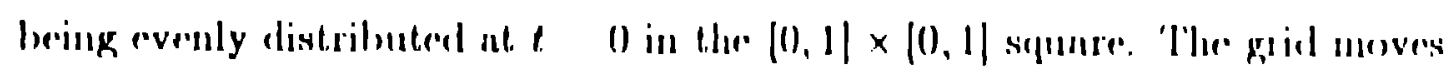
nt. t:er 'TW velocily, nucl $R$. 3.2

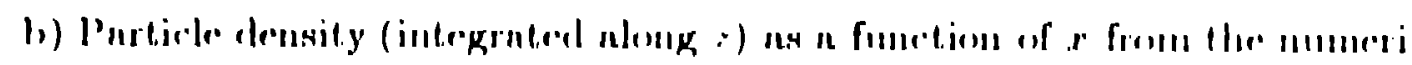

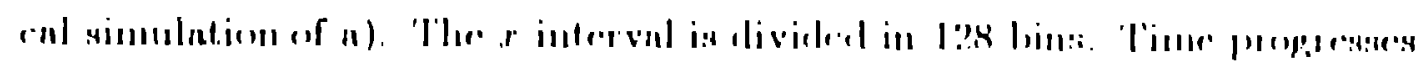


upwards, and the interval between profiles is 0.5 units of time.

Fig. 18: a) As in fig. 17a, for $R=1.1$

b) As in fig. $17 \mathrm{~b}$, for $R=1.1$

Fig. 18: a) As in fig. 17a, for $R=0.5$

b) As in fig. 17b, for $R=0.5$

Fig. 20: Contours of equal $H$ on the $(\xi, \zeta)$ plane bounded by $0, \pi$ in both directions.

Different value of $R$ are signified above each figure. 


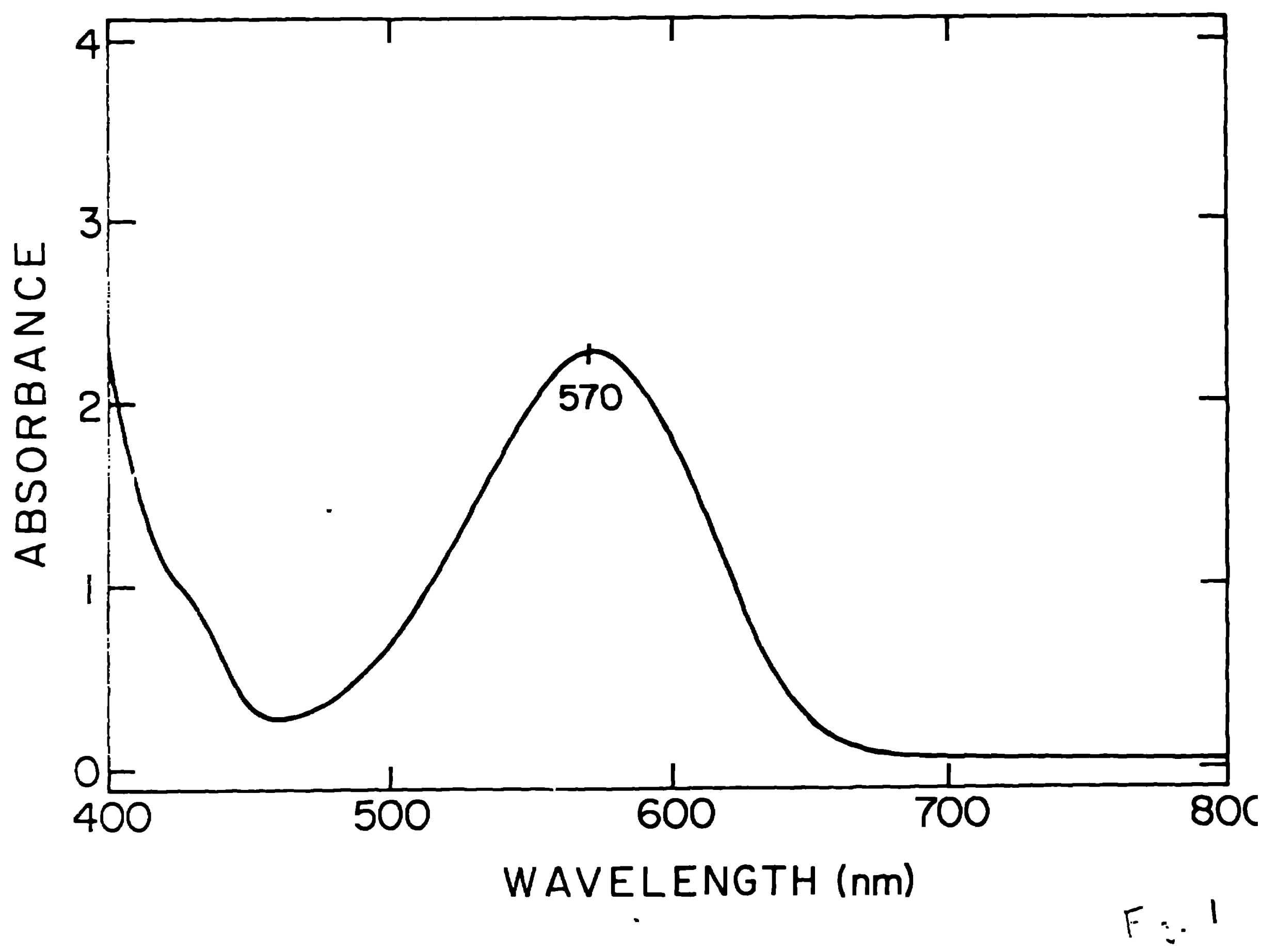




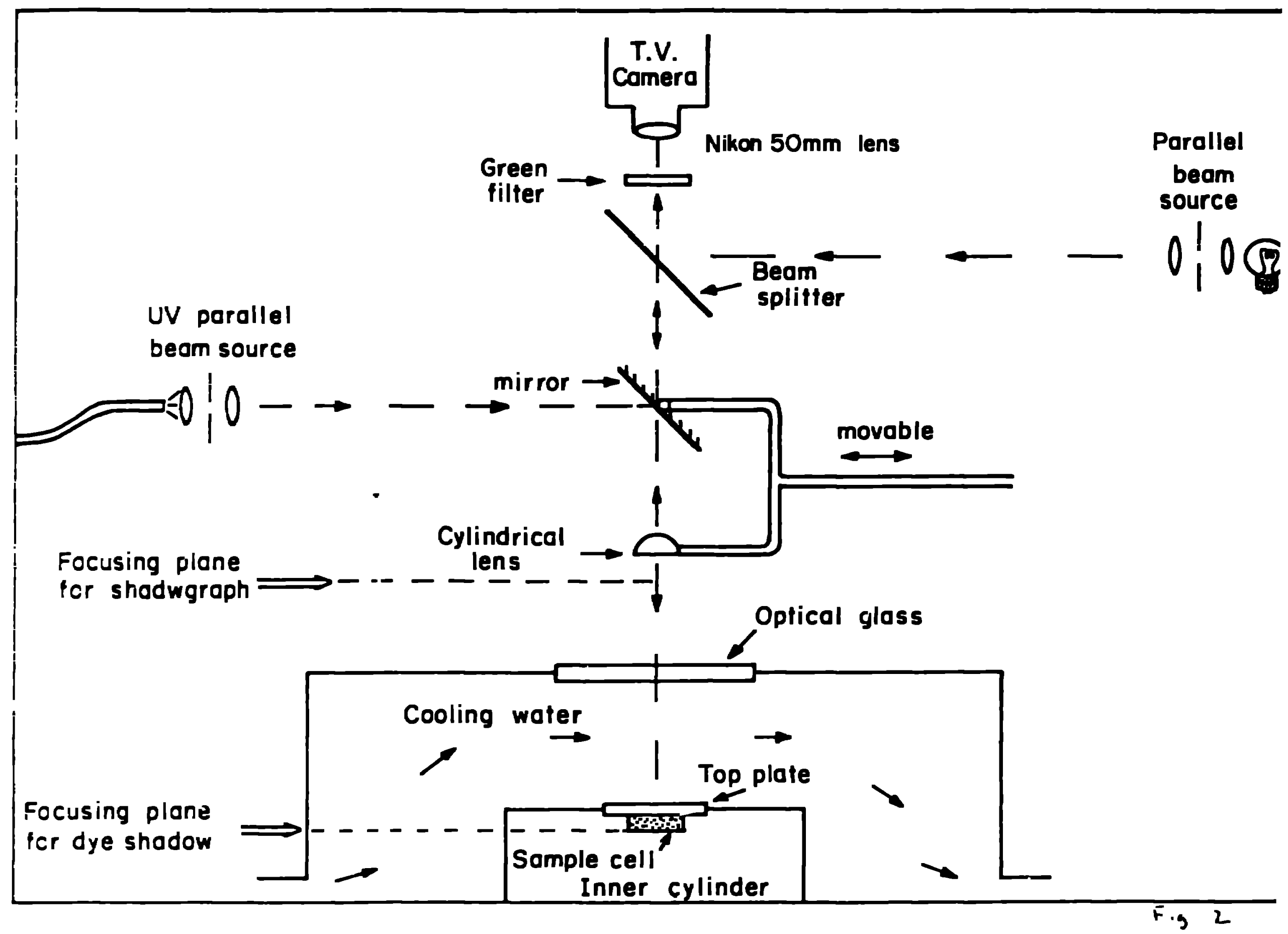




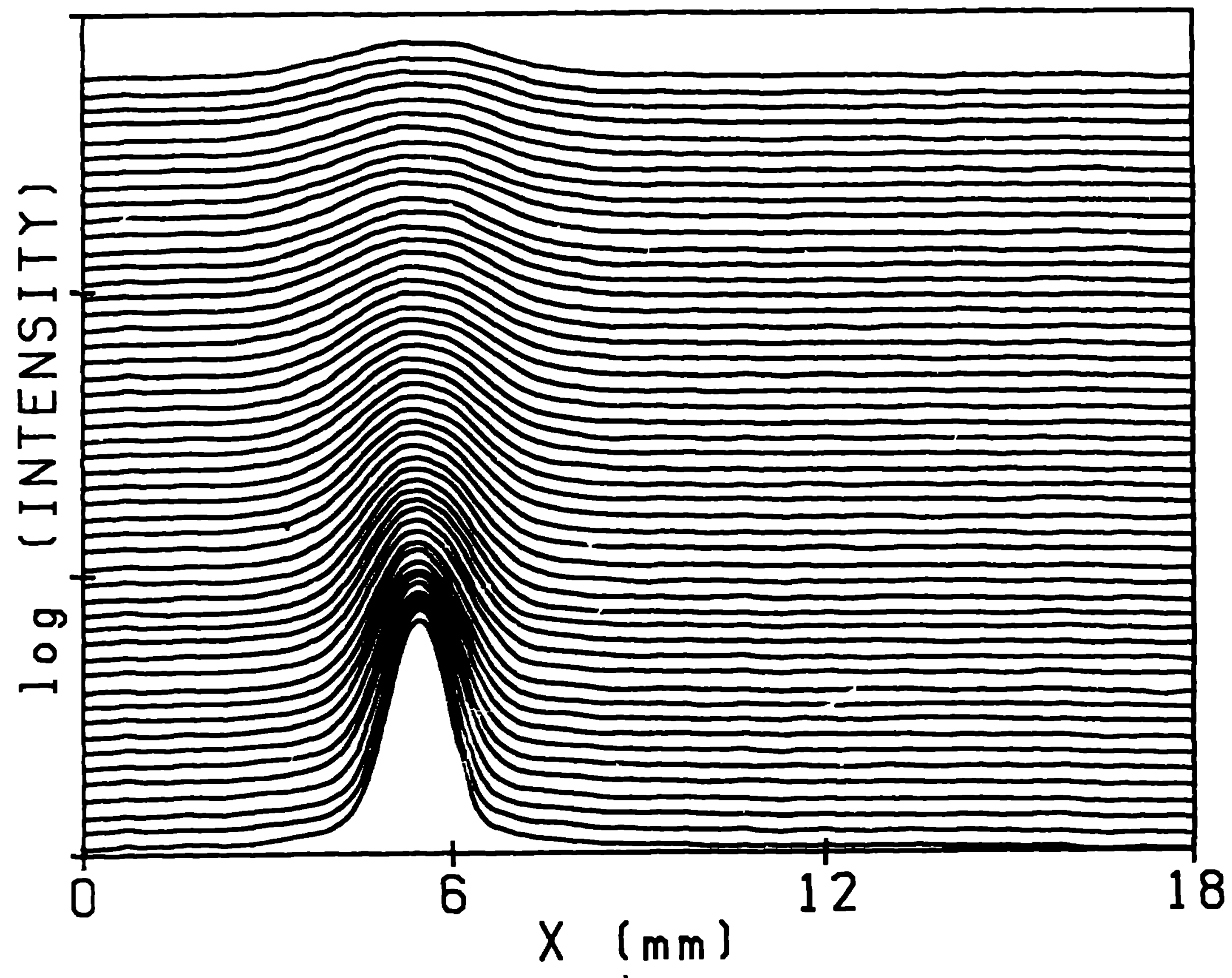

F.e 3 


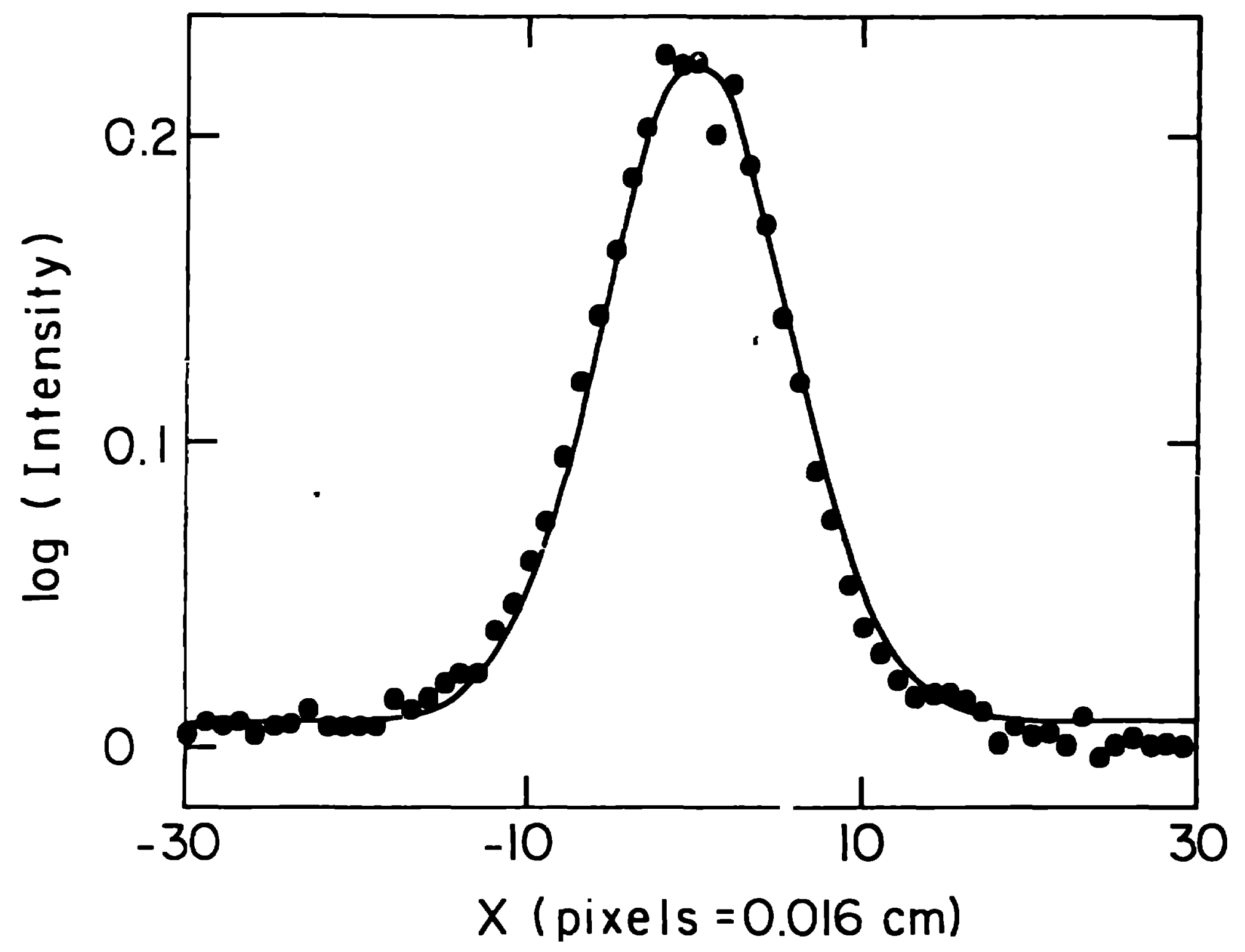

F.g. 4 


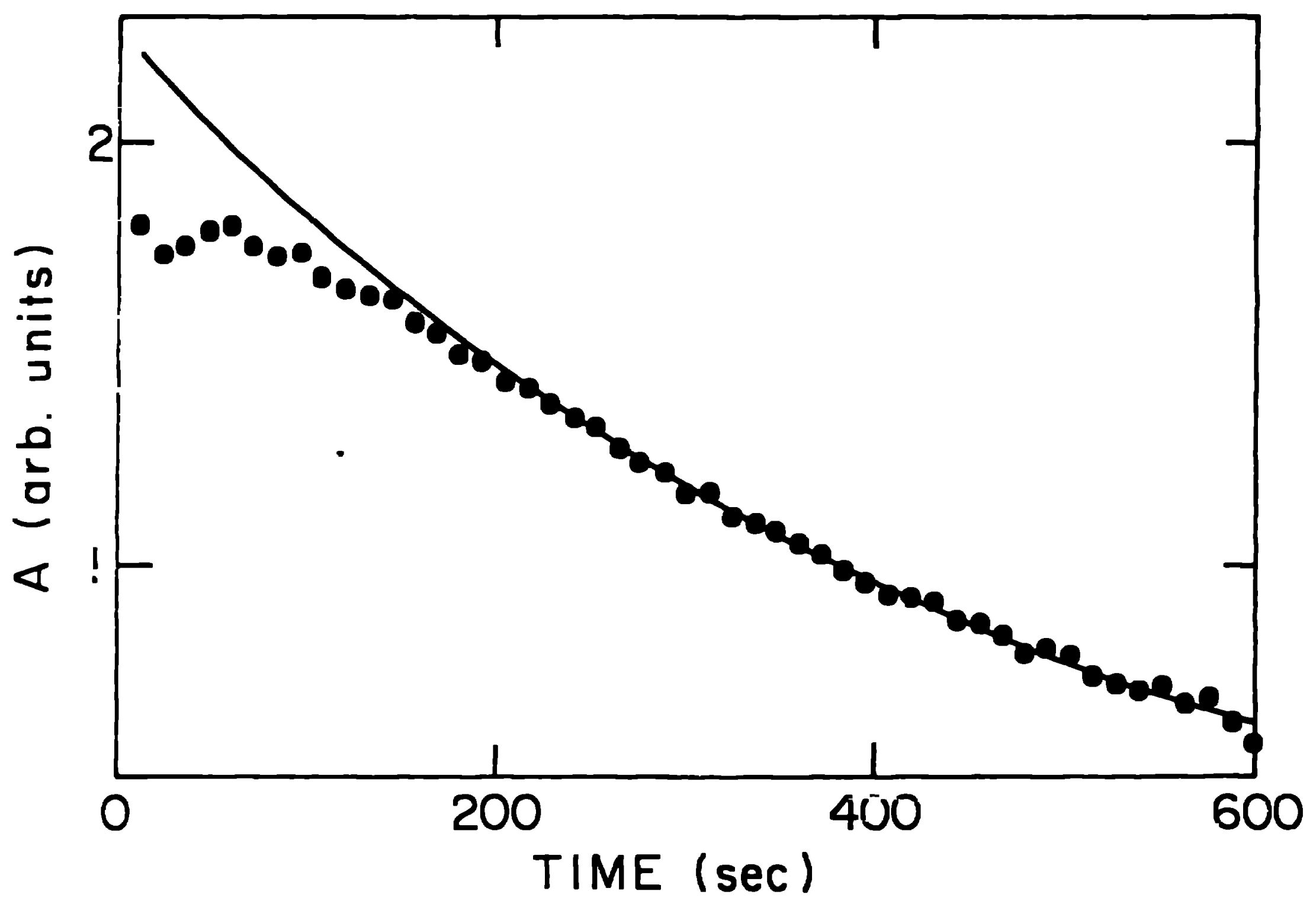

F.g. : 


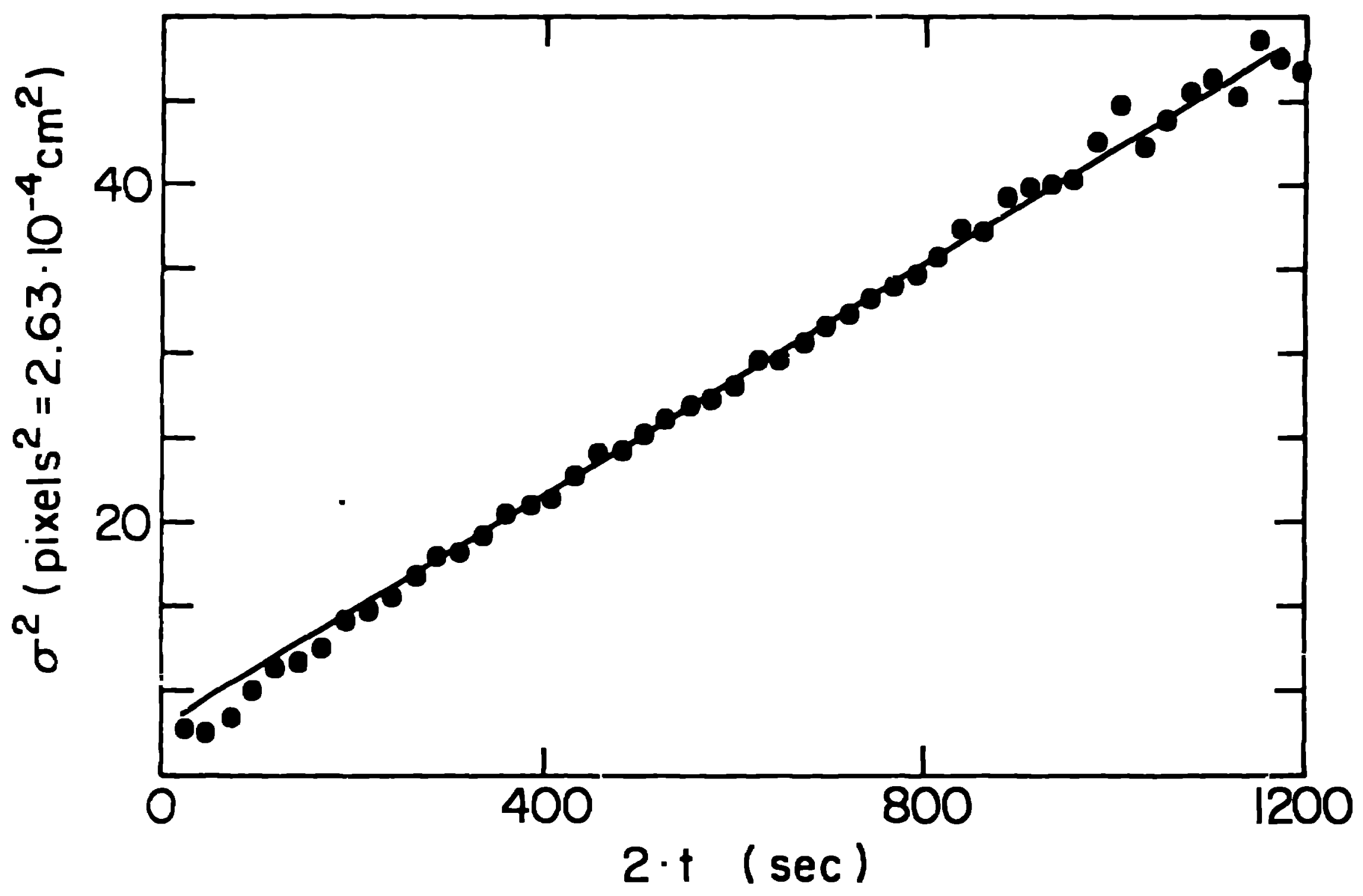

$F \cdot 96$ 


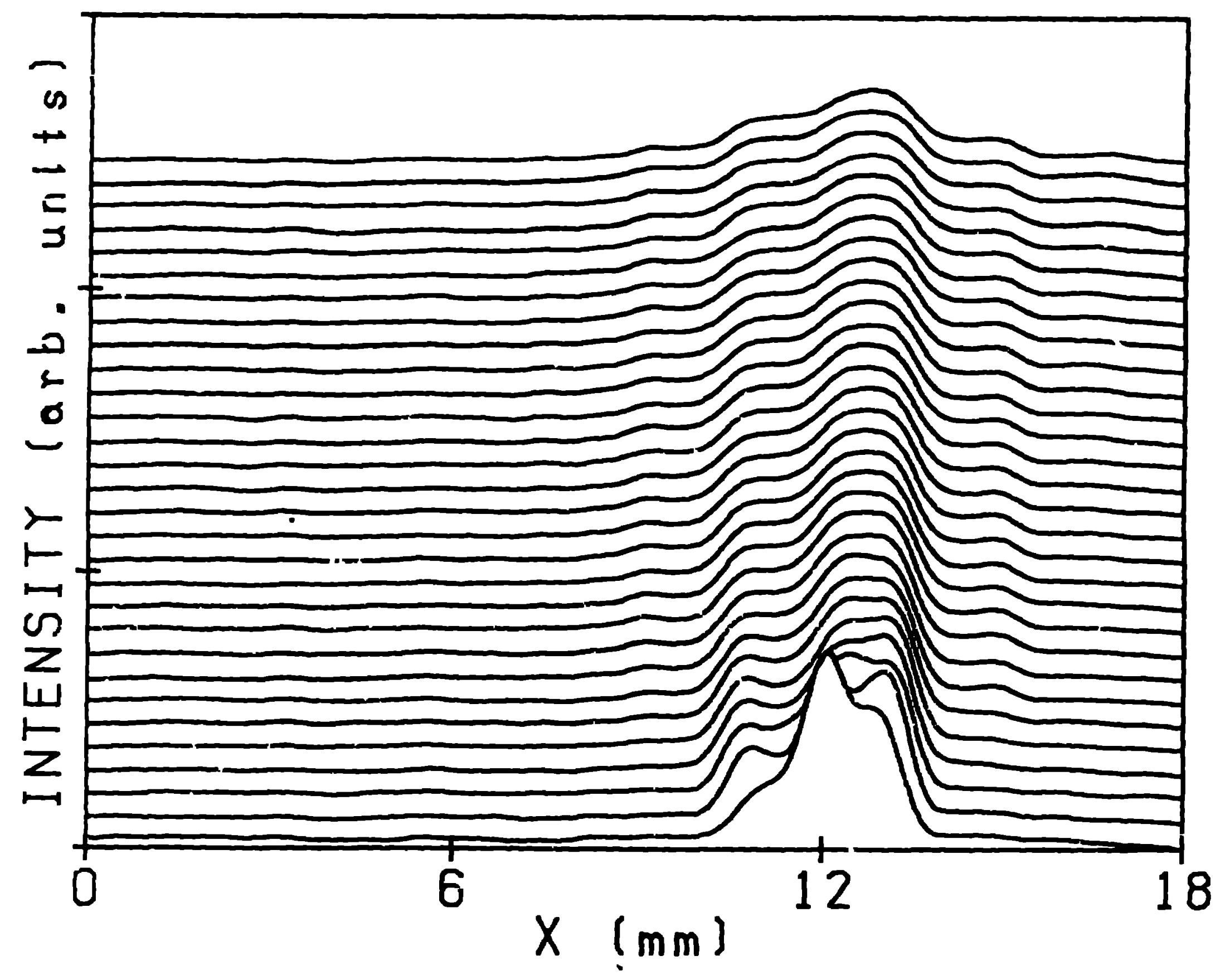

F.g. 7 


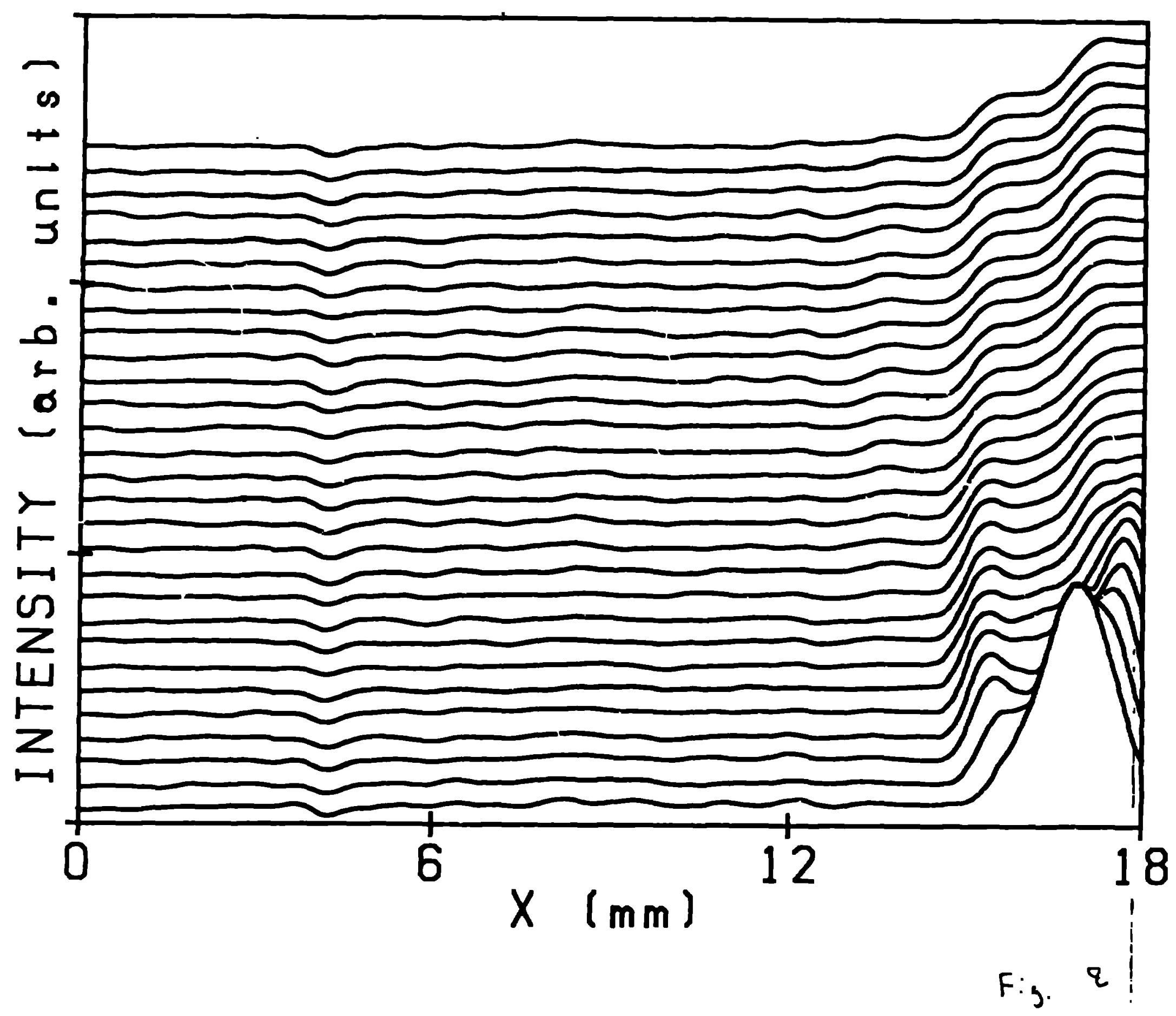




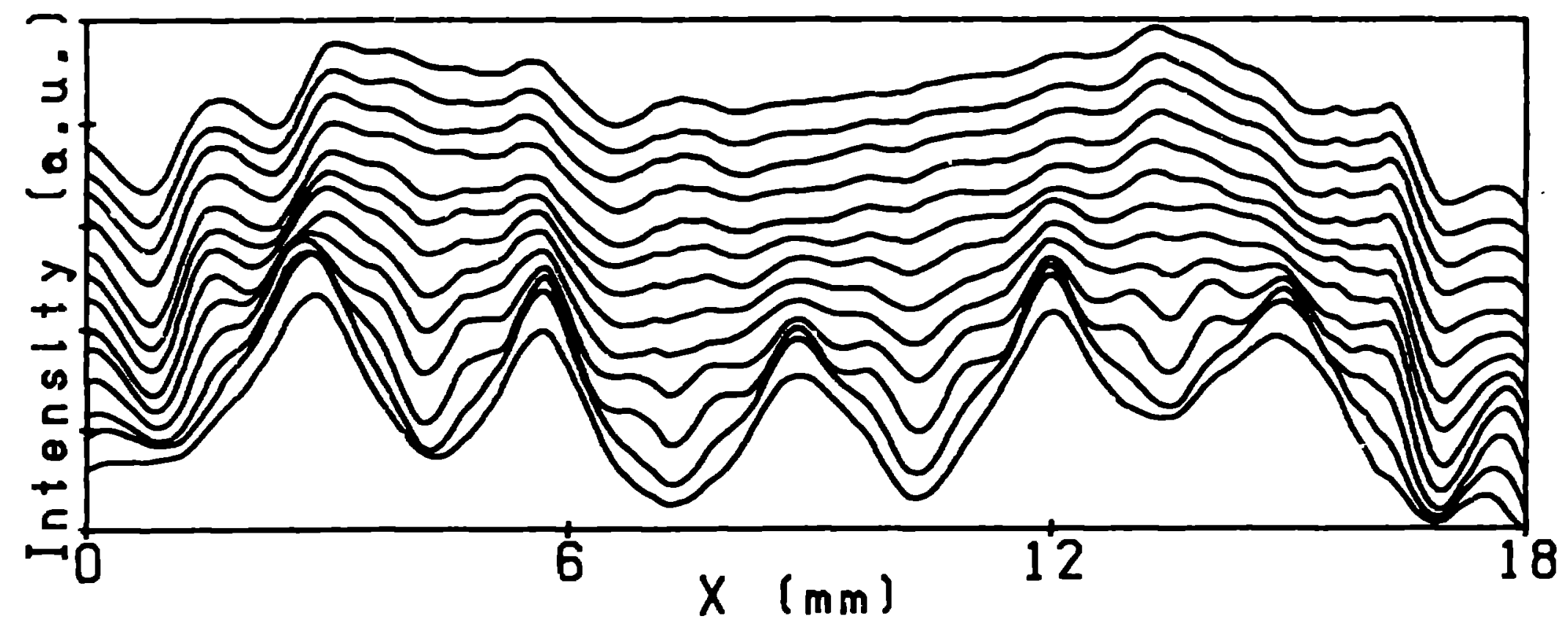

$r$. 


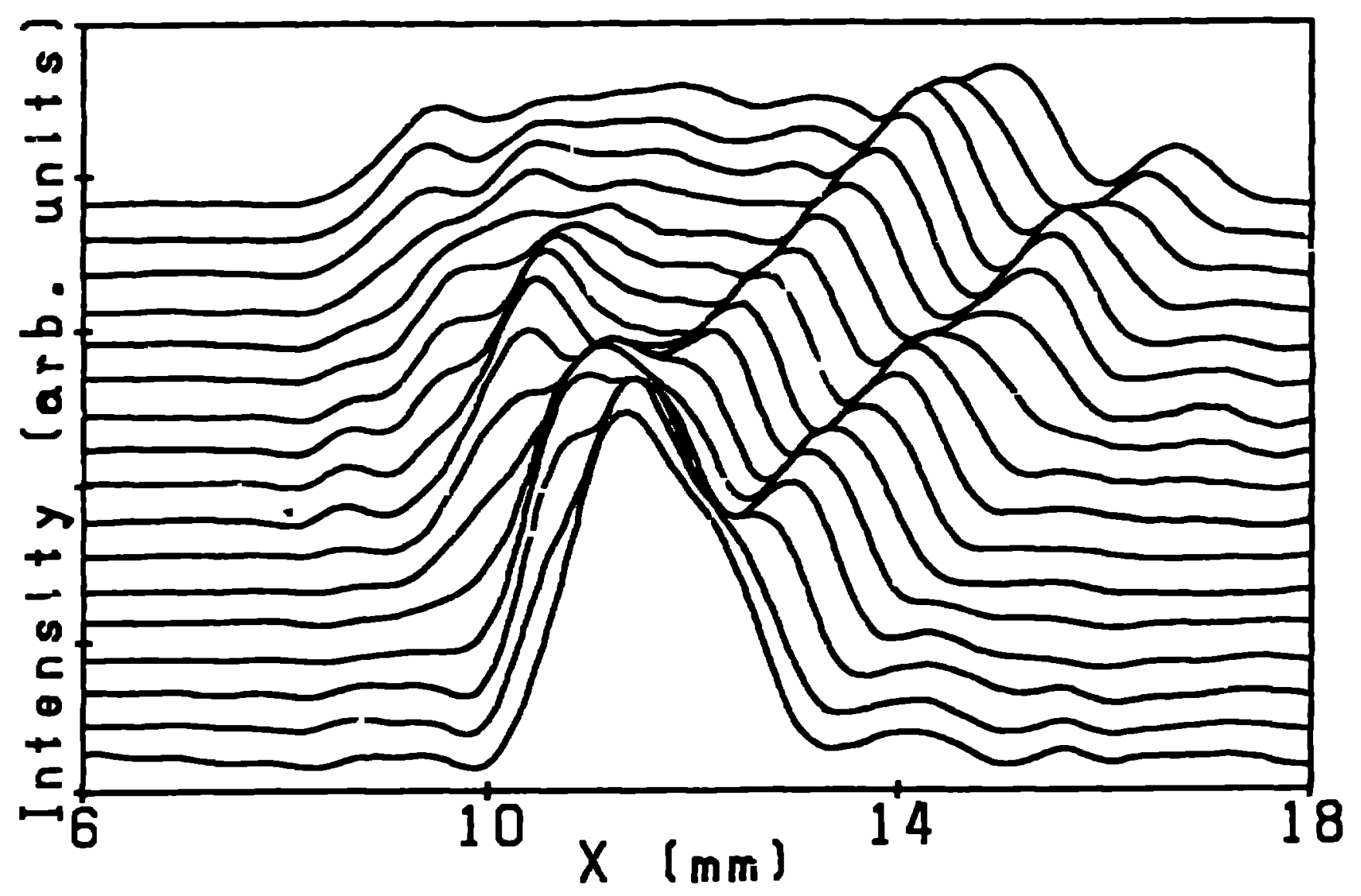

Fig. in 


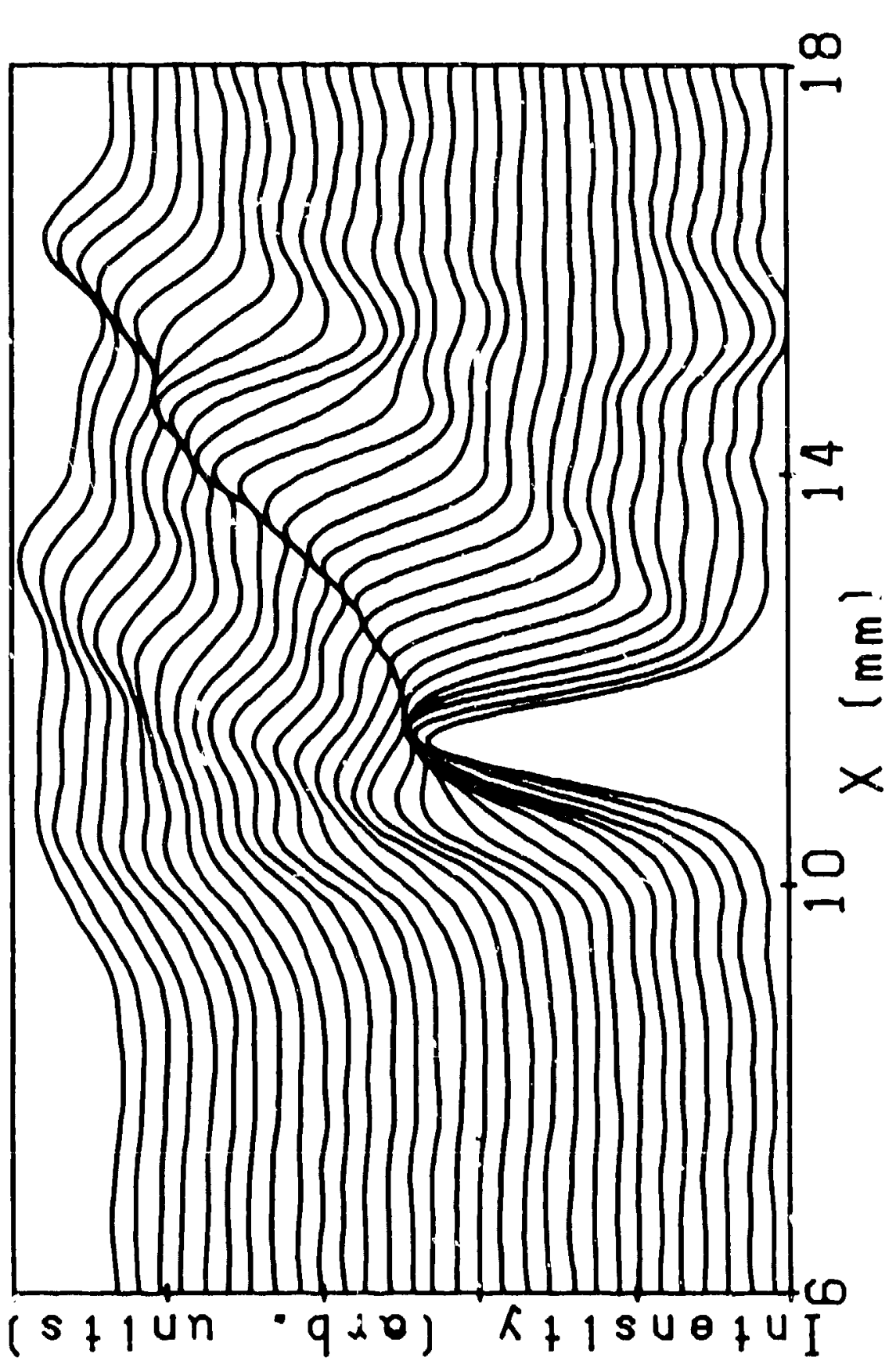




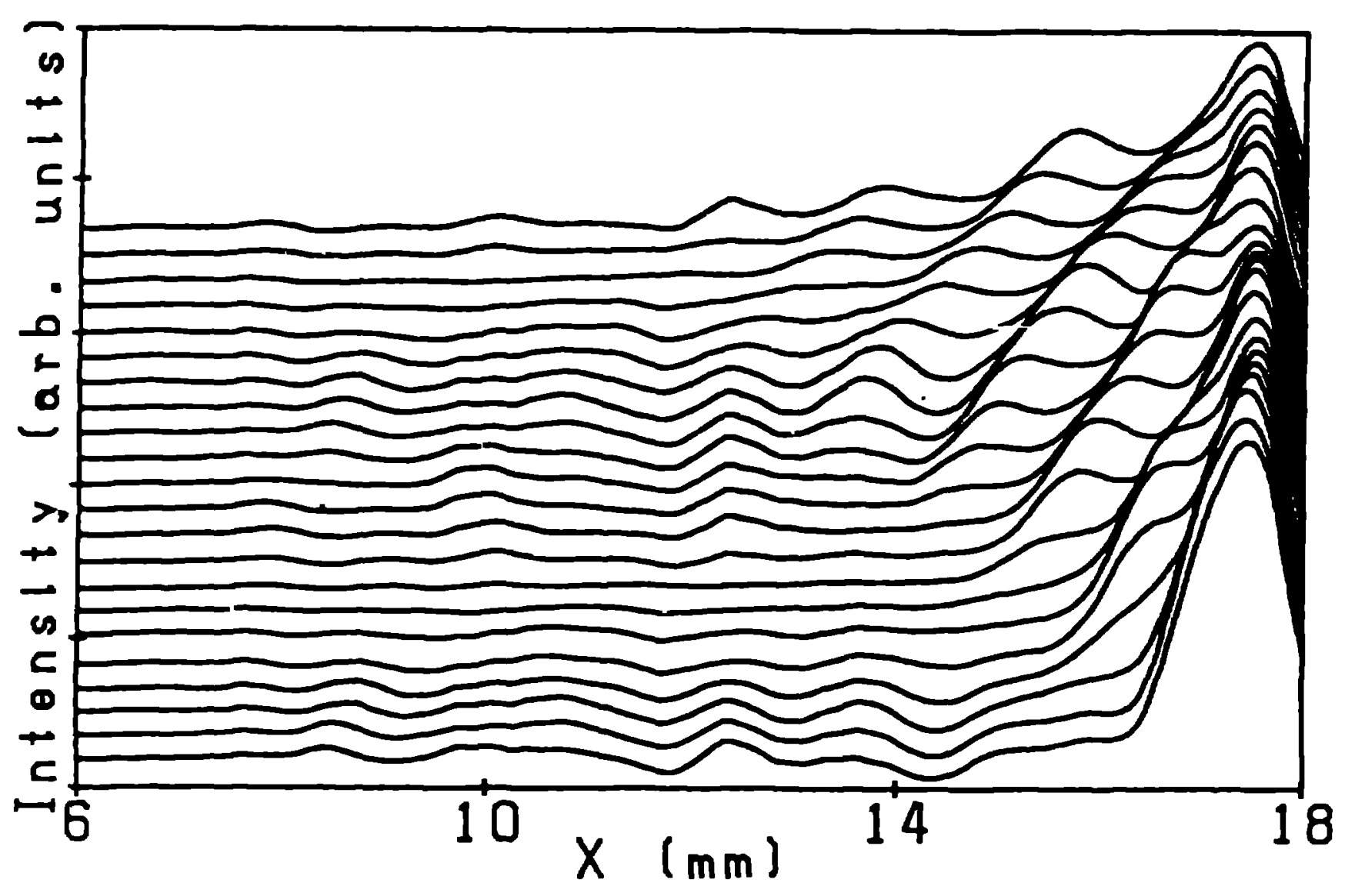

$F_{j}$ is 

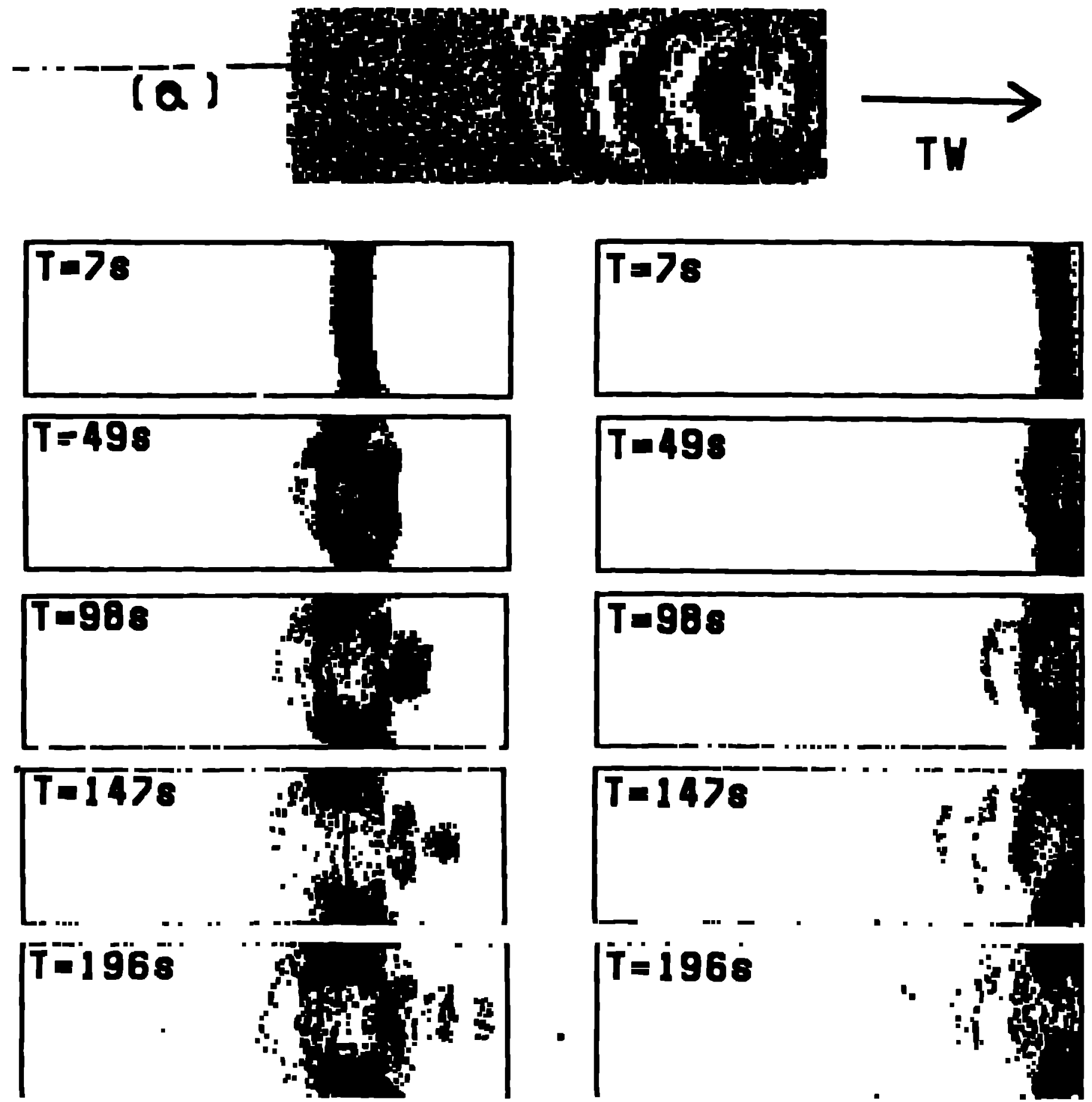

$T=238 s$

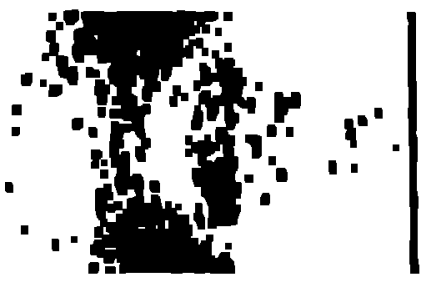

$T=2388$

(b) 


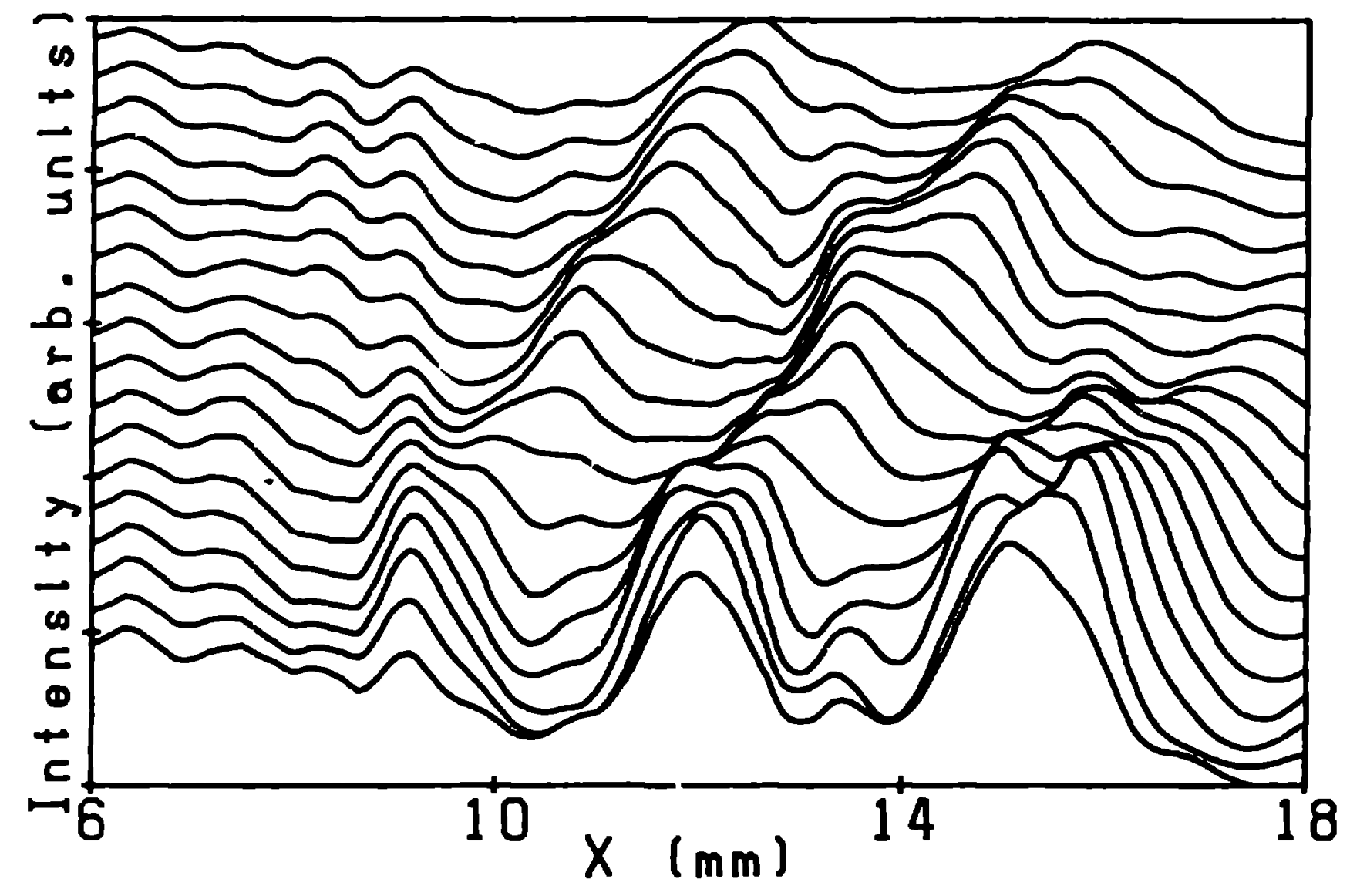

F.: : 


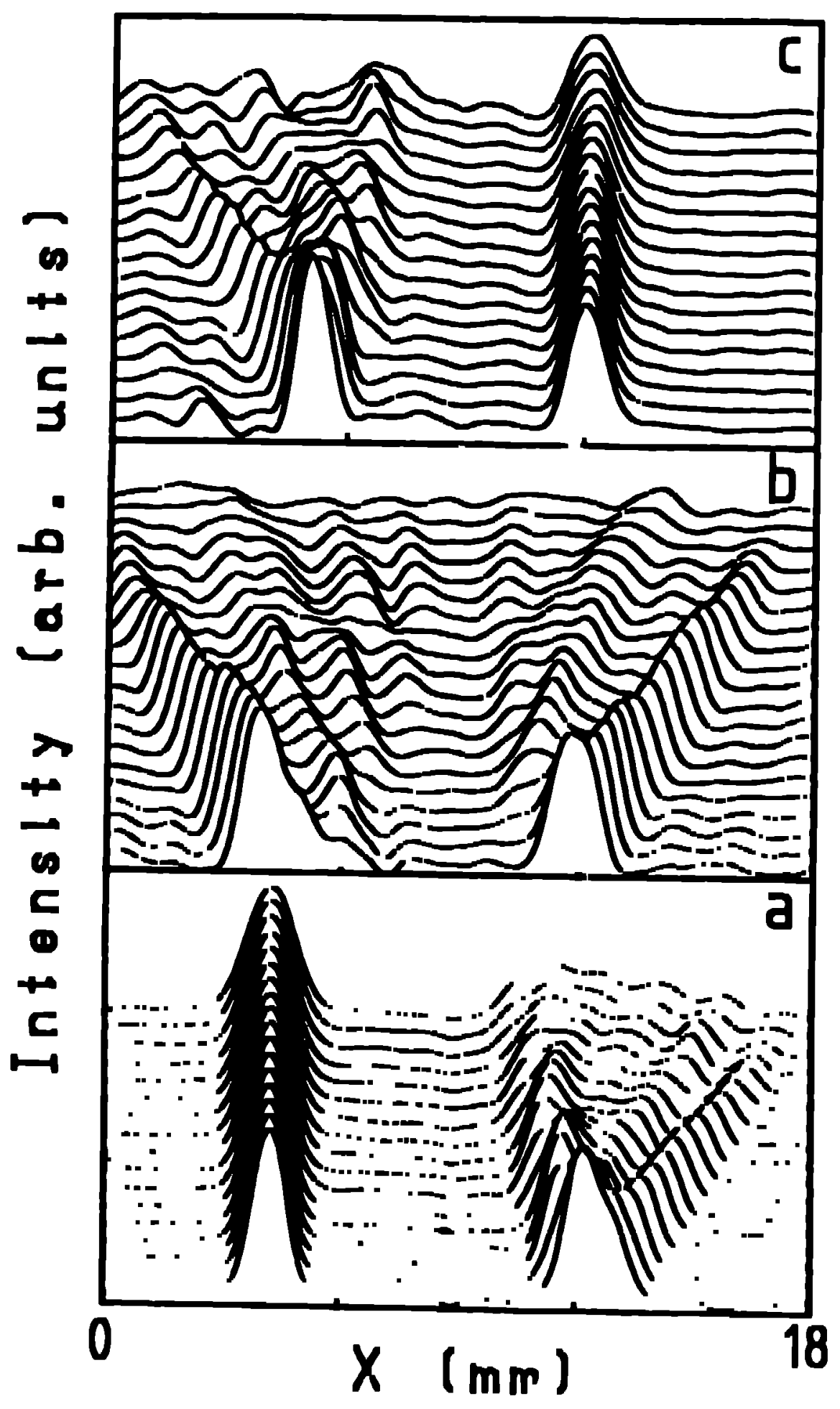

1.11 


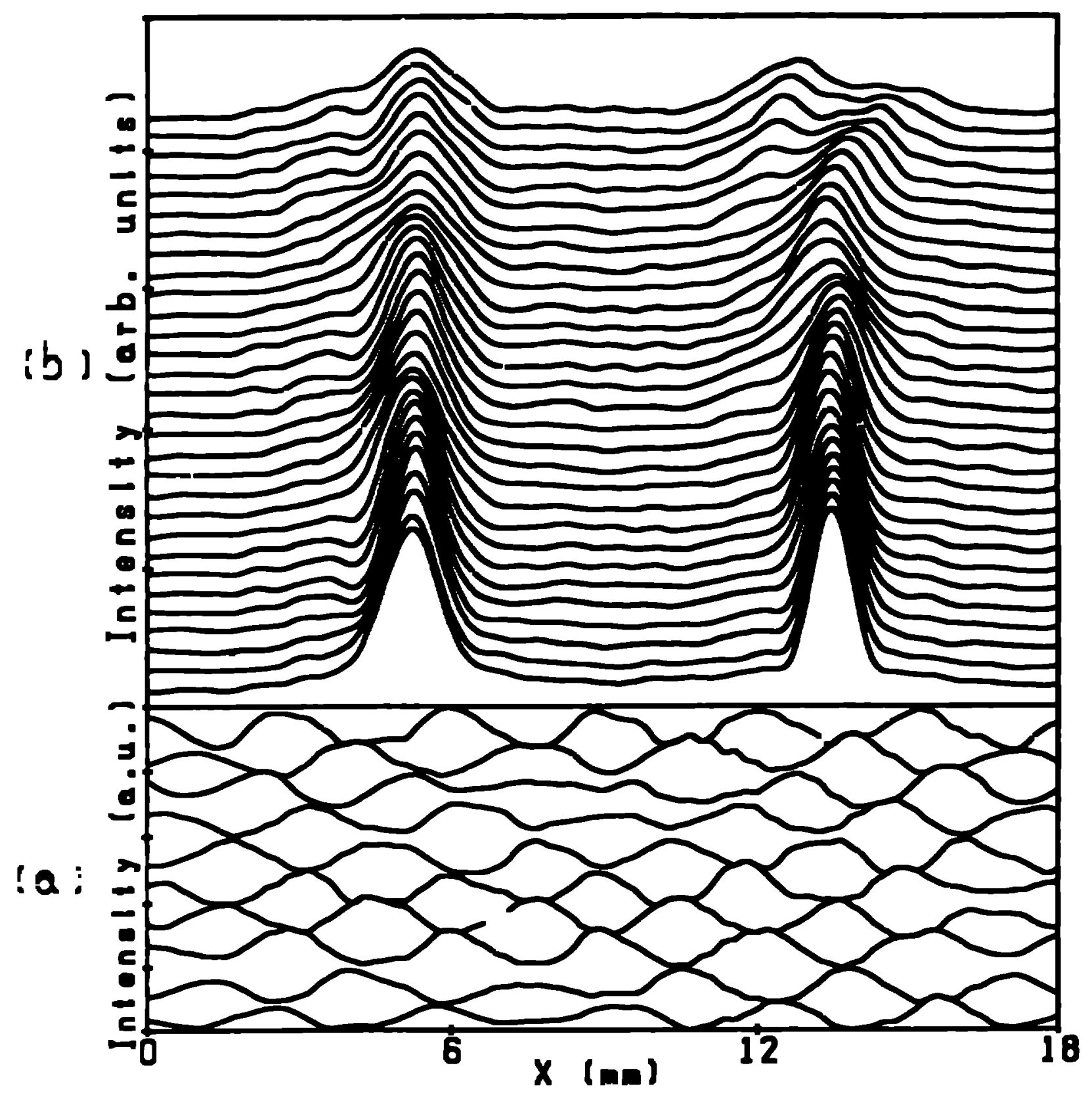




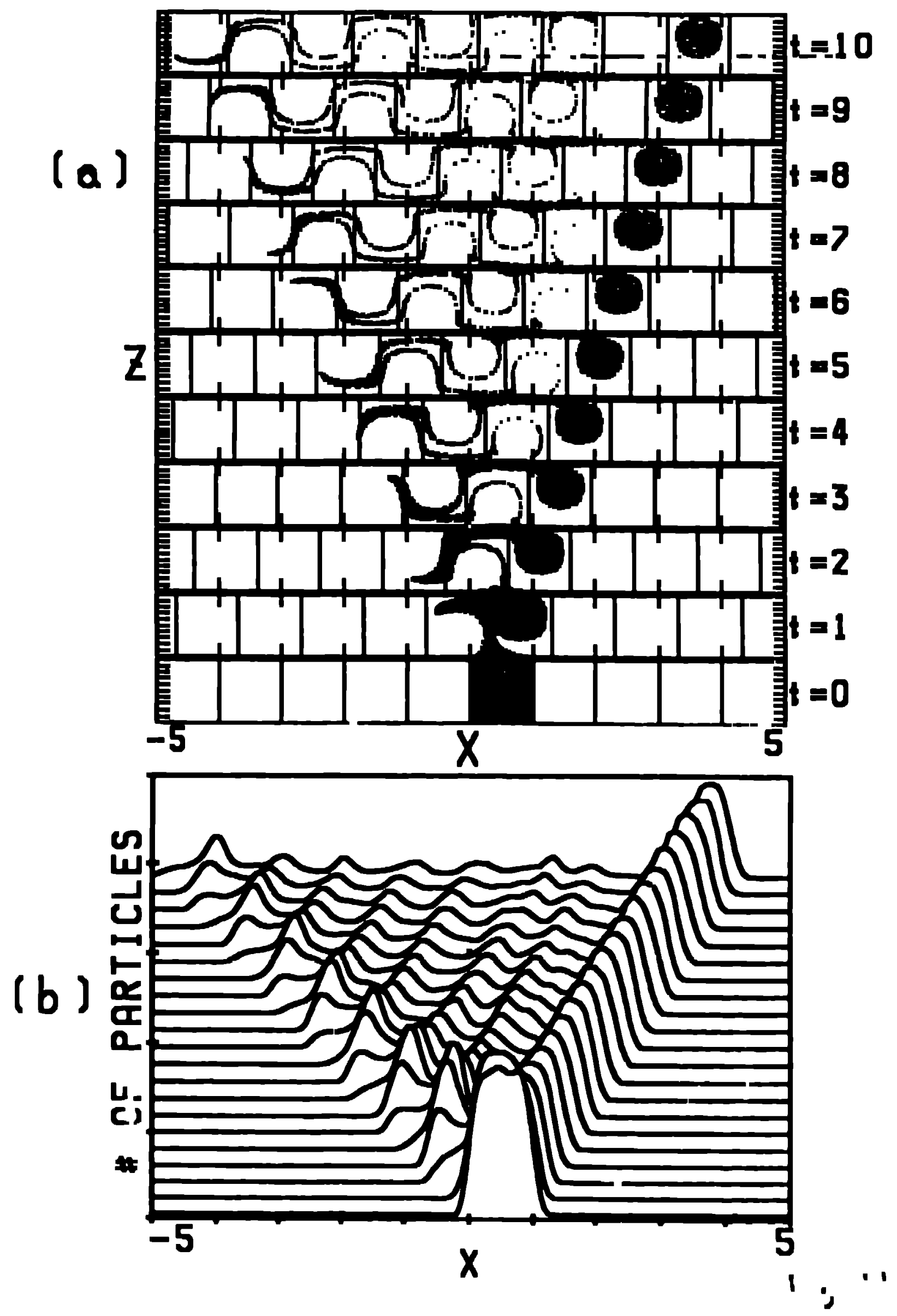




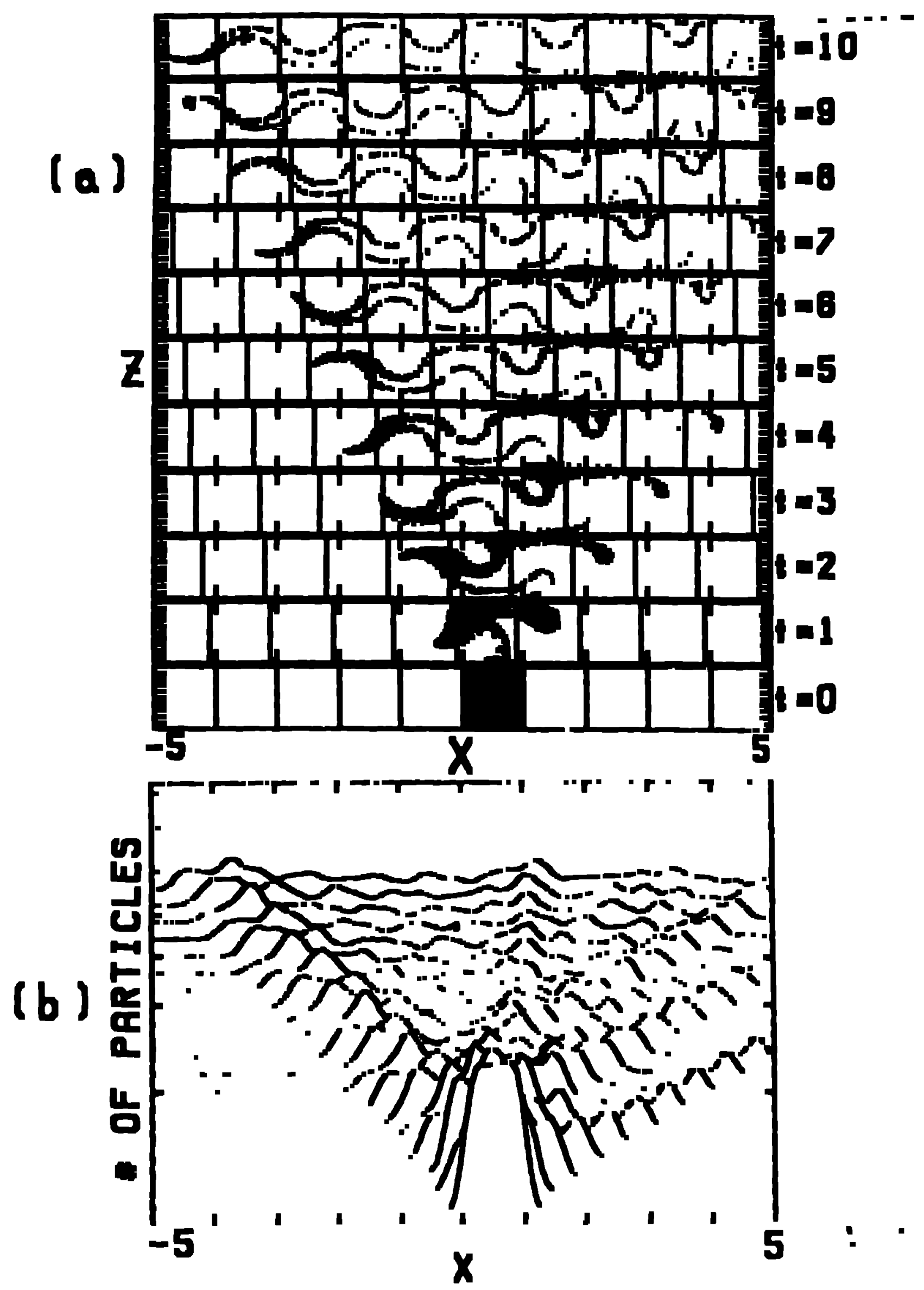




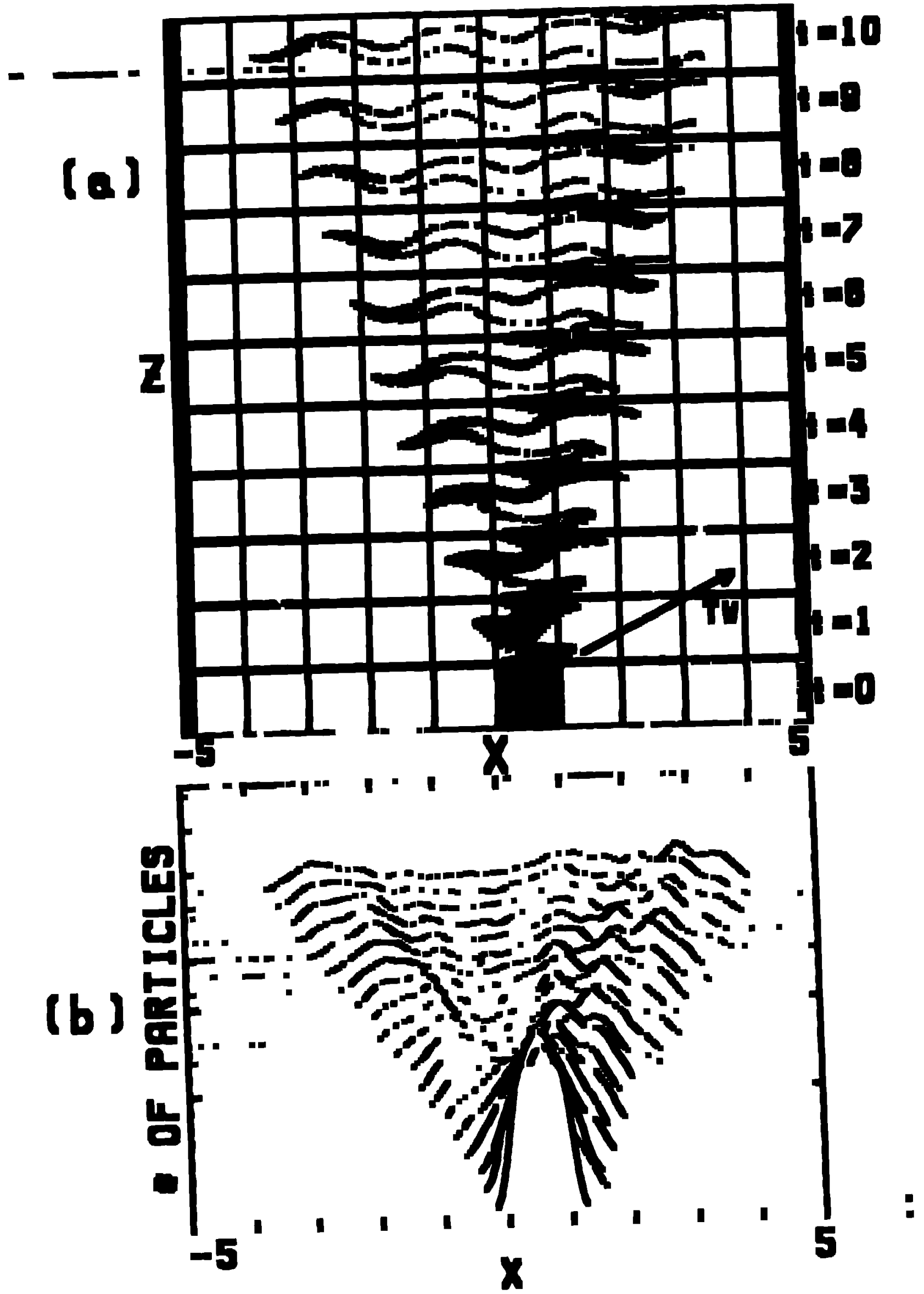



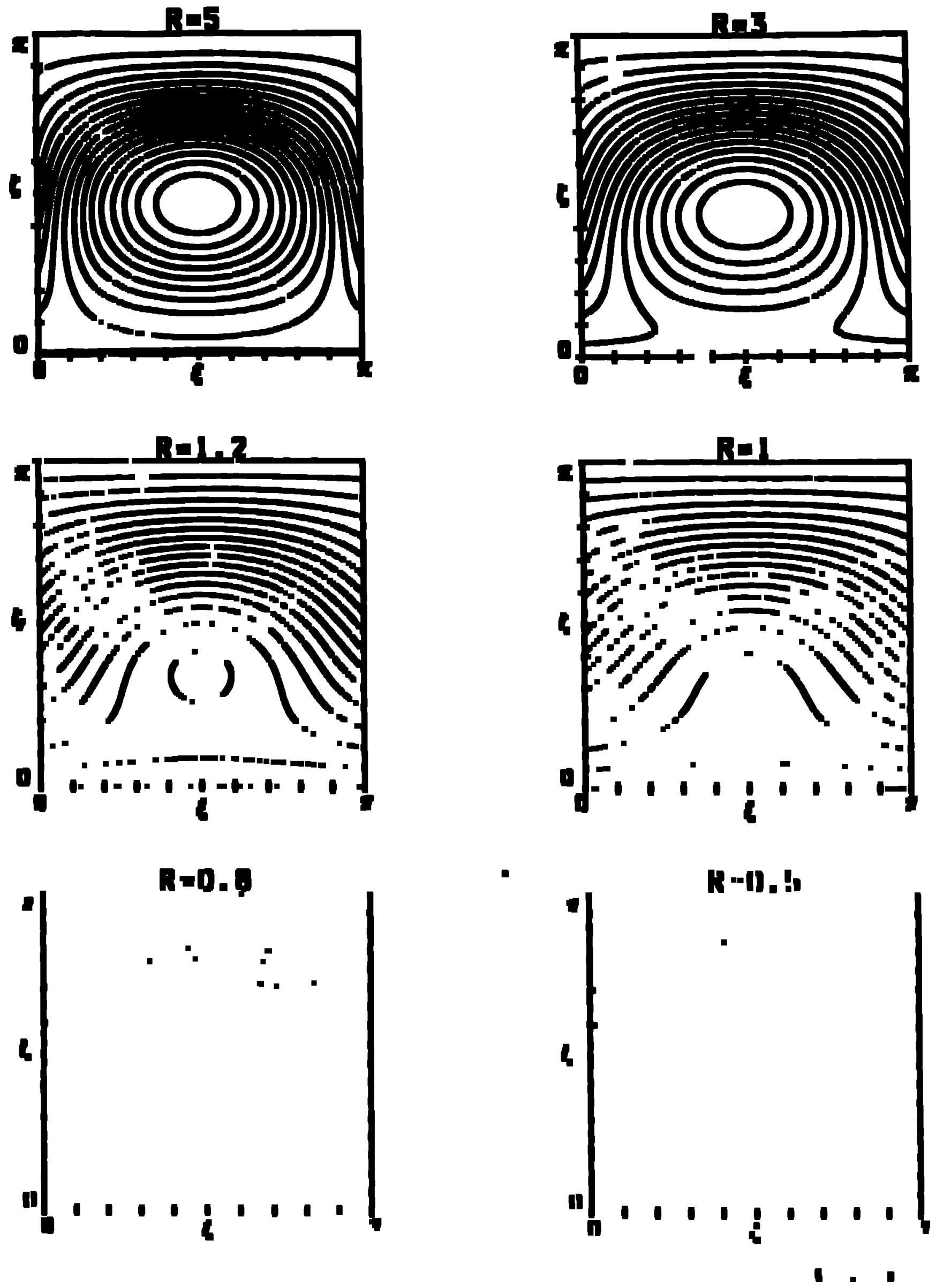